\title{
Applications of smart grid technology in Nepal: status, challenges, and opportunities
}

\author{
Tek Narayan Bhattarai ${ }^{1} \cdot$ Swastik Ghimire ${ }^{1} \cdot$ Bandita Mainali $^{2,3} \cdot$ Shiva Gorjian $^{4} \cdot$ Helen Treichel $^{5}$. \\ Shukra Raj Paudel ${ }^{1,6}$
}

Received: 25 October 2021 / Accepted: 2 February 2022 / Published online: 9 February 2022

(c) The Author(s), under exclusive licence to Springer-Verlag GmbH Germany, part of Springer Nature 2022

\begin{abstract}
Energy transformation and sustainability have become a challenge, especially for developing countries, which face broad energy-related issues such as a wide demand-supply gap, extensive fossil fuel dependency, and low accessibility to clean energy. Globally, smart grid technology has been identified to address these affairs and enable a smooth transition from traditional to smart energy systems, ensuring energy security. This paper studies the critical role in strengthening the power system, integrating renewable sources, electrifying the transport sector, and harnessing bioenergy. Evaluating the current energy scenario in Nepal, this article presents the smart grid as a solution to existing and future energy issues and the associated challenges during its implementation, urging concerned authorities to launch initiatives to promote it. Moreover, this study also lays the foundation for future research into the smart grid's potential to reform the power sector in other developing nations with abundant renewable energy sources and similar energy-related barriers.
\end{abstract}

Keyword Smart grid technology $\cdot$ Microgrid $\cdot$ Renewable energy $\cdot$ Energy transition $\cdot$ Challenges $\cdot$ Nepal

\section{Introduction}

Non-renewable resources such as fossil fuels are finite. Their continued use has evident health and environmental consequences owing to greenhouse gas (GHG) emissions, air pollution, water pollution, land degradation, and waste production (Yadav et al. 2020). To solve these issues, long-term initiatives aimed at achieving global sustainable development are required (Gorjian et al. 2019). However, a country's social and economic growth would be impossible without effective administration and the use of existing renewable energy sources (RESs) (Gorjian and Ghobadian 2015). Therefore, having access to renewable energy has become wastewater treatment.

-High capital cost and lack of policy restraint in smart grid implementation.

Shukra Raj Paudel

srpaudel@ioe.edu.np

1 Department of Civil Engineering, Pulchowk Campus, Institute of Engineering, Tribhuvan University, Pulchowk, Lalitpur 44700, Nepal

2 School of Engineering, Faculty of Science and Engineering, Macquarie University, Sydney, Australia

3 School of Engineering and Mathematical Sciences, La Trobe University, Bendigo, VIC 3550, Australia
4 Biosystems Engineering Department, Faculty of Agriculture, Tarbiat Modares University (TMU), Tehran, Iran

5 Laboratory of Microbiology and Bioprocesses, Department of Environmental Engineering, Federal University of Fronteira Sul - UFFS, Erechim, RS, Brazil

6 Department of Environmental Engineering, College of Science and Technology, Korea University, Sejong, Republic of Korea 
decisive in achieving social, environmental, and economic progress. Nepal is one of those developing nations which is currently underutilizing its potential RESs: with a per capita electricity consumption of 267 kilowatt hours (kWh) in 2020 (Himalayan News Service 2020). Therefore, there is a need to modernize the conventional energy system, following the path of other developed/developing countries to meet respective energy targets.

According to International Renewable Energy Agency (IRENA), the share of renewable energy in total global electricity production should increase from $33.3 \%$ in 2018 to $85 \%$ in 2050 to restrict global average temperature rise below $2{ }^{\circ} \mathrm{C}$, as mentioned in Paris Climate Agreement 2015 (IRENA 2018). At the end of 2020, the total renewable energy capacity reached 2799 Gigawatts $(\mathrm{GW})$ globally, and its share in total production has increased from $33.3 \%$ in 2018 to $36.6 \%$ in 2020 . Hydropower $(1,211 \mathrm{GW})$ provided the largest renewable share, with the wind (733 $\mathrm{GW})$ and solar photovoltaic (PV) (714 GW) accounting for the majority of the remaining share (IRENA 2021a). China (31.97\%), the United States (US) (10.43\%), Brazil (5.36\%), India (4.79\%), and Germany (4.72\%) (Fig. 1a) each contributed a significant part of the global renewable energy generating capacity (IRENA 2021b). Globally, renewable energy generation capacity has been significantly rising yearly (Fig. 1b) because of the advancement of smart technologies, encouraging the integration of RESs like solar PV and wind power via the transformation of conventional grids into smart grids.

The energy transition from non-renewable to renewable has been emerging as a global energy plan (Fuentes et al. 2020). Therefore, the average annual rise of global renewable energy consumption has been significantly increased by $8.62 \%$ (Fig. 1b). Heavy dependence on conventional
Fig 1 a Global share of renewable energy 2020, and b Globally generated annual renewable energy over the past years (Data Source: (IRENA 2021b))

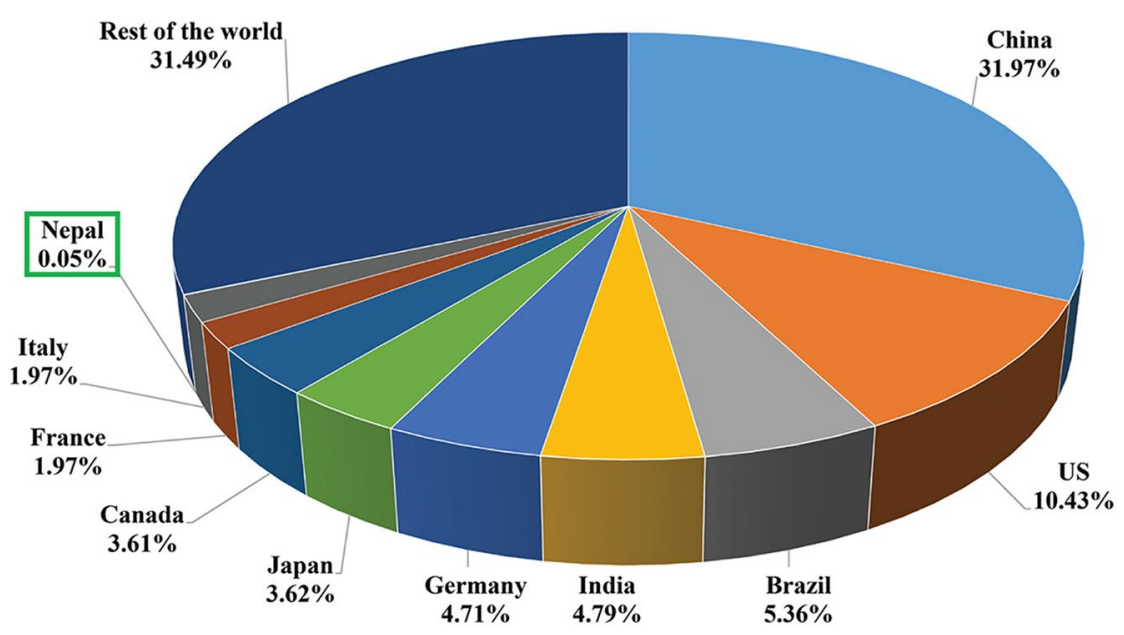

(a)

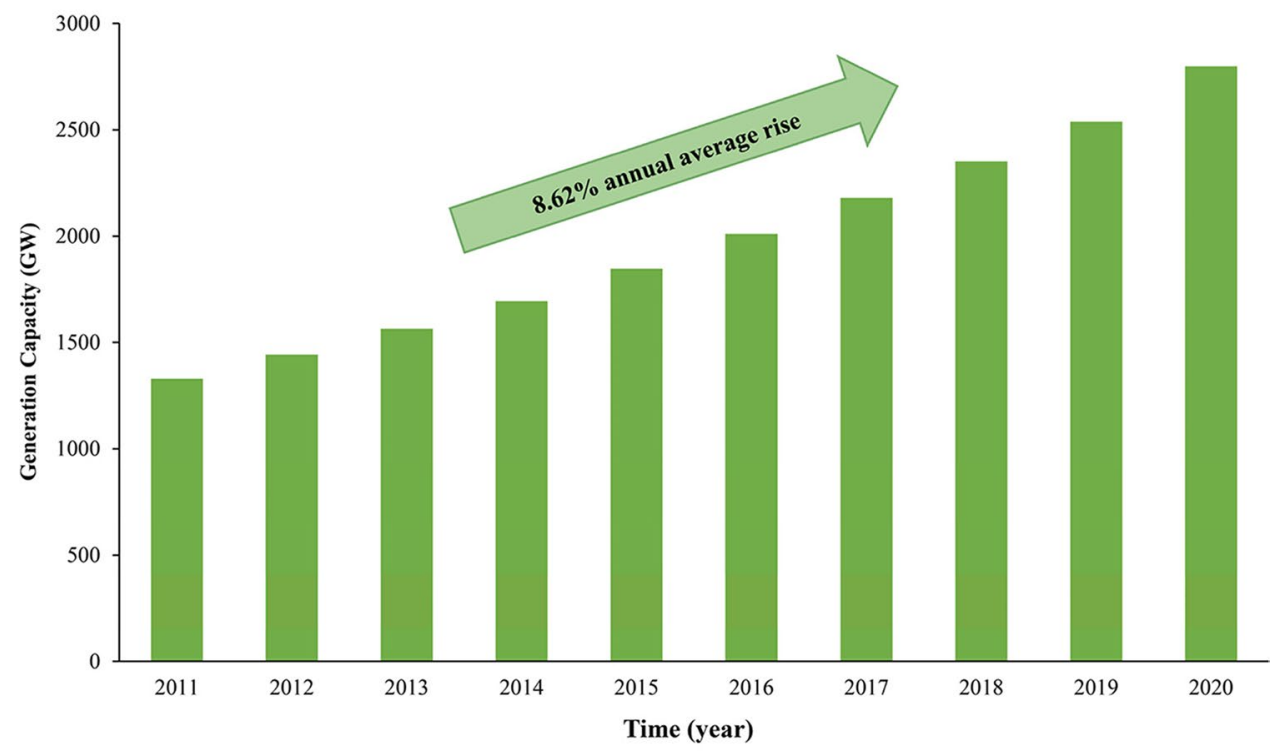

(b) 
fuels has raised concerns over environmental and socioeconomic sustainability (Sovacool et al. 2011); therefore, the focus of Nepal's energy policies needs to shift from traditional energy technology to smart and efficient energy technology. Hence, transforming existing power grids into smart ones is crucial to boost energy transition and achieve sustainable development goals. However, limited studies have evaluated the need for this technological shift, and few have recognized smart grid technology as a viable option for achieving Nepal's sustainable energy transformation.

Thus, the primary aim of this study is to offer a tool to assist Nepal's energy sector transformation/reformation. More specifically, this paper explores different technologies that aid in smart grid transition and management of micro-grids and aims to highlight the role of electric vehicles and wastewater treatment in promoting sustainable energy in the future. It discusses the technical, managerial, and legal barriers that emerge in smart grid implementation, and thus devises necessary solutions/ roadmap that can be adopted to overcome them. Moreover, to achieve 2050's global target of $85 \%$ share of renewable energy in total electricity production, all developing countries should emphasize efficacious incorporation of their available RESs through making their grid flexible and innovation-friendly by adopting a smart grid strategy. Therefore, this paper highlights and encourages its essentialness and opportunities in developing countries like Nepal for achieving the global goal of a sustainable and clean energy future. Finally, based on the findings in the context of Nepal, this study proposes suitable policies and institutional frameworks that can be relevant to transforming energy sector in developing countries, and thus also suggests prioritization of investments in Renewable Energy Technologies (RETs) in the future.

For the literature review, the "Google Scholar" search engine (scholar.google.com) was used, and research articles, mostly after the year 2000, were reviewed. Keywords like "smart grids," "renewable energy," "technology," "hydropower," "solar power," "wind energy," and "sustainability" etc. were used for the search. Data and energy status were reviewed through National Electricity Reports and thoroughly compared with National Reports from other countries like India, Bangladesh, and Brazil. Moreover, secondary data regarding current global energy scenarios, electricity demand and capacity, and transmission network in Nepal were obtained from IRENA, Water and Energy Commission (WECS), and World Bank, respectively. Reports from Asian Development Bank as well as relevant literatures were also analyzed to discuss the status of the development of some technologies, as well as to underline some key issues and barriers in those realms. Finally, National Policy Reports were reviewed, and the policy implications of smart grid technologies were discussed alongside the managerial implications.

\section{Smart grids}

The term Smart Grid was, presumably, first coined in a paper titled "Toward a smart grid: power delivery for the twenty-first century" in 2005 (Massoud Amin and Wollenberg 2005). The Smart Grids European Technology Platform has defined a smart grid as "an electricity network that can smartly integrate the actions of all users connected to it generators, consumers and those that do both-to efficiently deliver sustainable, economic, and secure electricity supply" (Vesnic-Alujevic et al. 2016). Some European countries and the US realized the necessity of modernization of the power grid in the 1980s and made significant progress in transforming the smart grid (Simões et al. 2011). In contrast, developing countries like Nepal have only recently realized its need to effectively manage produced energy, reduce power loss, and appropriate utilization of potential RESs.

\section{Global perspective}

Smart Grids have been globally popular since the mid-2000s and progressively developed worldwide, most remarkably in the US, the UK, Italy, Japan, and South Korea. During the initial phases of smart grids development, the US and the European Union (EU) aired numerous pilot projects, deploying smart grid applications such as smart meters, electric vehicles (EVs), distributed generation, smart network management, etc. (Simões et al. 2011). Currently, they are focused on increasing energy efficiency and RES inclusion, bolstering and broadening their linkage between countries and states (Ponce-Jara et al. 2017; Gorjian et al. 2021). Despite China being a latecomer to smart grid deployment, its expenditures on smart grid projects mainly focused on high-voltage transmission networks have already surpassed those of the US. Meanwhile, developing nations India and Brazil are investing/advancing their efforts to transform their grid by initiating many developments and reform programs with the formation of various commissions, regulations, and acts (Asaad et al. 2019; Dranka and Ferreira 2020). Their programs include installing smart meters, applying geographic information systems in distribution networks, and energy derivation from alternate sources. Their efforts are chiefly converged to electricity theft detection and loss reduction (Ponce-Jara et al. 2017).

Bangladesh and India are also facing various power supply issues. With heightening demand and dependence on coal- and oil-based power plants, Bangladesh is susceptible to the heavy blow from the ongoing energy crisis (Uddin and Taplin 2006). The ongoing affairs of its power system are poor and aging power system infrastructure, limited fossil 
fuel resources, high losses, low renewable energy usage, and high GHGs emissions. The Government of Bangladesh and its distribution companies have been inclined toward smart grid technology to incorporate available renewable sources in the primary grid and thus helps reduce dependence on carbon-intensive fossil fuel plants (Islam and Bloemink 2018). Facing similar problems, India has also been implementing smart grid technologies for energy security, limiting global warming, strengthening the renewable energy sector, and escaping the energy crisis (Singh and Tiwari 2017). Furthermore, the global trend of increasing renewable energy capacity over the previous decade (Fig. 1b) justifies the need for Nepal to make the transition toward smart grid technology.

\section{The current scenario in Nepal}

In Nepal's current power system, fragile transmission and distribution network, aging infrastructure, high transmission and distribution loss, power theft, poor RESs penetration, and heavy reliance on fossil fuels are significant concerns that need to be addressed promptly (The Kathmandu Post 2018). The Nepal Electricity Authority (NEA), to alleviate these issues, intends to set up 5 million smart meters in stages by 2025 . It had intended to station 98,000 smart meters in two distribution centers in Kathmandu Valley $(\mathrm{KaV})$ by May 2020 and 450,000 smart meters in 10 distribution centers in $\mathrm{KaV}$ by May 2021. However, due to complexities caused by the COVID-19 pandemic, only around 60,000 smart meters have been deployed, but still, immediate benefits like lower meter reading costs and reduction in losses have been realized in the early phases. Furthermore, it projects to set up a total of 3 million smart meters by May 2023 and 5 million smart meters by May 2025. Along with this, NEA has a target to take up several pilot projects (ADB 2018). It has started the Kathmandu Valley Substation Automation Project to make the grid system more reliable and smart, as well as lower operating costs and improve equipment service life. In addition, numerous high-voltage transmission lines $(400 \mathrm{kV})$ have been finished, and others are now being built or proposed (NEA 2021).

Recently, NEA has taken the initiative to install $50 \mathrm{EV}$ charging stations in essential places and highways across the country in response to the government's plan and policies to increase the share of EVs. On April 09, 2021, a contract was signed with M/s Wanbang Digital Energy Co., Ltd., China, with 1 year estimated time of completion, with the preconstruction survey work ongoing currently. Moreover, NEA has plans for extending the number of charging station up to 300 shortly (The Himalayan Times 2021). Regarding utilization of RESs, Nepal's first large-scale private-owned solar power plant of capacity 8.5 Megawatt (MW) was connected to the national transmission line by Ridi Hydropower
Company in Butwal (Bhusal 2020). Additionally, the Government of Nepal (GoN) has issued construction licenses to 15 solar power projects amounting total capacity of about 92 MW (DoED 2021). Geotechnical investigations and hydrological studies are currently underway in the BegnasRupa Pump Storage Hydroelectric Project (150 MW), while a Memorandum of Understanding (MoU) has been signed for the Environmental Impact Assessment (EIA) and geotechnical studies in the Kulekhani-Sisneri Pump Storage Hydroelectric Project (100 MW) (NEA 2021). Furthermore, the Department of Electricity Development (DoED) has granted licenses to many pump hydro-storage projects. The GoN and related authorities have established numerous policies and regulations in past years that promote various smart grid concepts as presented in Table 1 .

These initiatives and policies indicate that GoN and relevant stakeholders have realized the need to modernize and upgrade the power system. Still, progress is slow due to their complicated physical and socio-economic aspects. Therefore, the future trend is restructuring the Nepalese energy sector through smart grid technology to provide a high degree of energy security and reliability, which requires indepth discussion and analysis concerning its massive potential and benefits and associated challenges.

\section{The necessity for smart grid in Nepal}

Nepal's gradually improving economy needs safe access to modern energy technologies to exploit/utilize its vast RESs for long-term growth and prosperity. Therefore, transformation to smart grid technology is required to make better use of current infrastructure and include new technologies in the future. The main driving forces that necessitate Nepal's smart grid transition are addressed in the following sections.

\section{Meeting the rising demand}

In the past, the shortage of energy resulted in frequent and irregular power outages and load-shedding up to 12-14 h per day. It led to losses of about US\$24.69 million yearly in the industrial sector (Poudyal et al. 2019). It was facilitated through preliminary strategy and plan adopted by NEA and GoN to mitigate the crisis by controlling electricity loss and increasing performance of electrical energy system (ADB 2017). The NEA has managed to reduce the losses from $25.78 \%$ in FY $2015 / 16$ to $17.18 \%$ in FY 2020/21 (NEA 2021), but still, it is almost double when compared with the average world loss $(8.25 \%$ ) (The World Bank 2018). Compared with some South Asian countries, loss in India is about $20 \%$ (The Economic Times 2021), 11.8\% in Bangladesh (BPDB 2019), and 8.34\% in Sri Lanka (CEB 2018). 


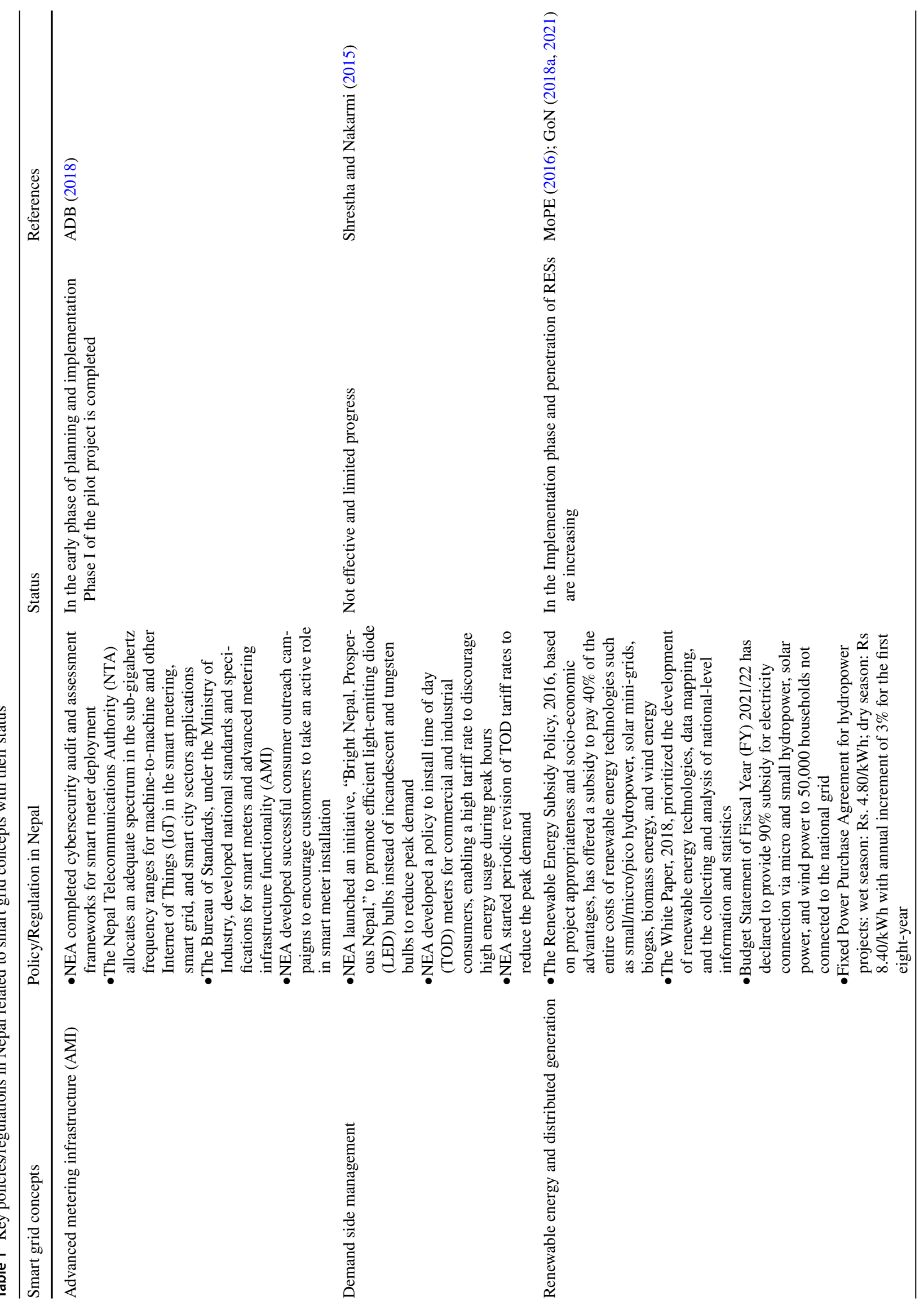




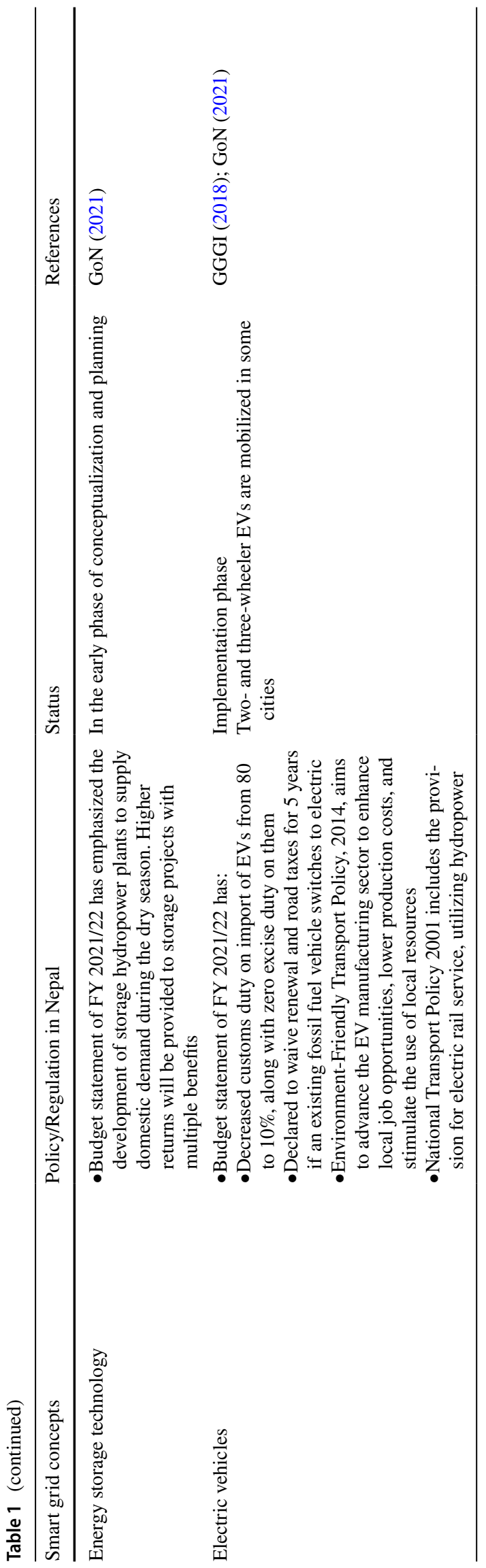

The critical factors for creating such a wide demand-supply gap throughout the past years were primarily attributed to incompetent plans to diversify generation, transmission, and distribution systems and setbacks in project completion in time. In recent years, by promoting local production, import, and effective demand-side management via coordinated resource utilization, Nepal has successfully annihilated load-shedding. Still, it persistently continues experiencing the antagonistic effects of inadequate and inconsistent power supply due to various problems depicted in Fig. 2. Furthermore, the total generation capacity has increased gradually from $706 \mathrm{MW}$ in 2011 to $1900 \mathrm{MW}$ in 2021, while the peak demand has overgrown from 946.10 to $1500 \mathrm{MW}$ (ADB 2017; NEA 2020, 2021; DoED 2022).

If not resolved by adopting an appropriate strategy in time, these problems will surely make the energy system of Nepal more vulnerable to a broad demand-supply gap and frequent power failures when required to meet the high demand in forthcoming years. Water and Energy Commission Secretariat (WECS) has modeled electricity demand for 25-year planning period under different scenarios as depicted in Fig. 3. The higher the GDP growth rate, the higher will be the demand. Also, the same study has projected the installed capacity required, as presented in Fig. 4, to meet the electricity demand in the corresponding scenario. According to the World Bank, the annual GDP growth rate was $6.657 \%$ in 2019 (The World Bank 2020), so we expect it to reach a high scenario soon. To meet such high demand, the existing power grid of Nepal needs sheer modernization to ensure better management of produced energy, reducing losses to acceptable limits, utilization of domestic resources curtailing import, and a flexible distribution system.

\section{Electrification of the transportation sector}

The transportation sector is among the rapidly expanding sector of Nepal, which is responsible for consuming a significant portion of fossil fuel and GHGs emissions. The percentage of fuel consumed by the transportation sector in total fuel consumption has jumped from $49 \%$ in 2007 to $67 \%$ in 2017 (Zhou et al. 2020). With a rise in consumption, the emission of GHGs like $\mathrm{CO}_{2}$ has also elevated inexorably. In $2017,45.4 \%$ of overall $\mathrm{CO}_{2}$ emission was released by the transportation sector in Nepal (Zhou et al. 2020). Such emission has contributed to air pollution and global warming, which have a deteriorating effect on human health and the environmental ecosystem (Shrestha et al. 2017).

Therefore, to restrict the rising GHGs discharges from carbon-intensive technologies, it is suggested that the nation should take essential activities to shift to alternative low carbon technology. Electrifying the transport sector would be a sustainable solution to restrict GHG emissions (Kainuma et al. 2017). But the current scenario is quite the opposite, 
Fig. 2 Key causes and consequences of Nepal insufficient and unreliable power supply (Data Source: ADB 2017)
Fig. 3 Electricity demand at different scenarios with predicted ones (Data Source: (WECS 2017))

Fig. 4 Required installed capacity under different scenarios with predicted ones (Data Source:(WECS 2017))

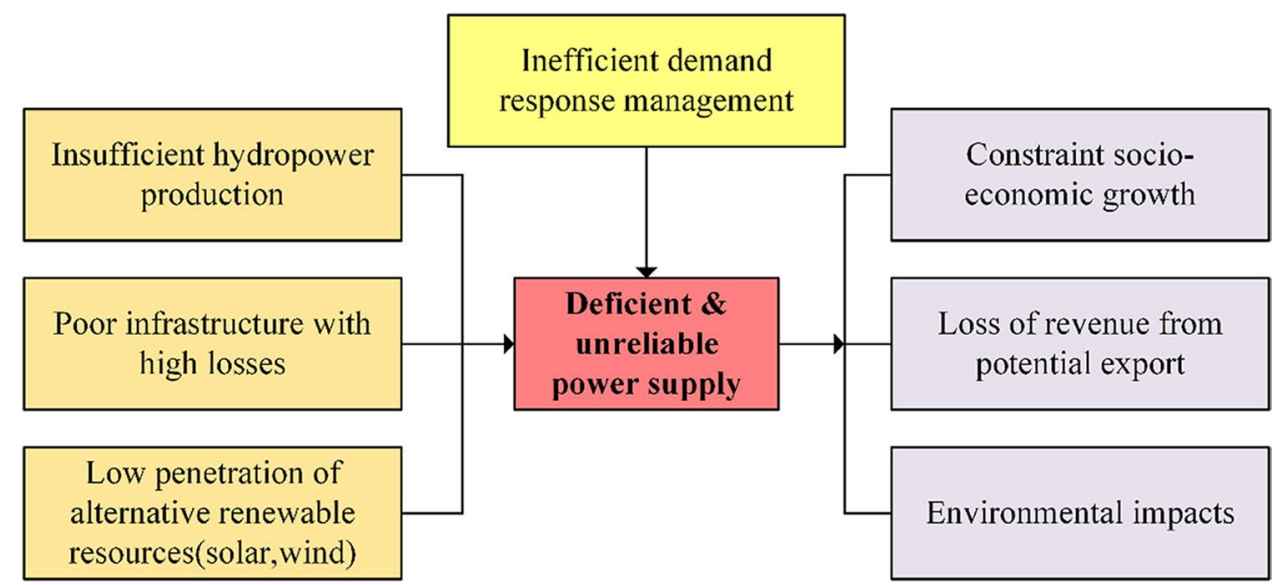

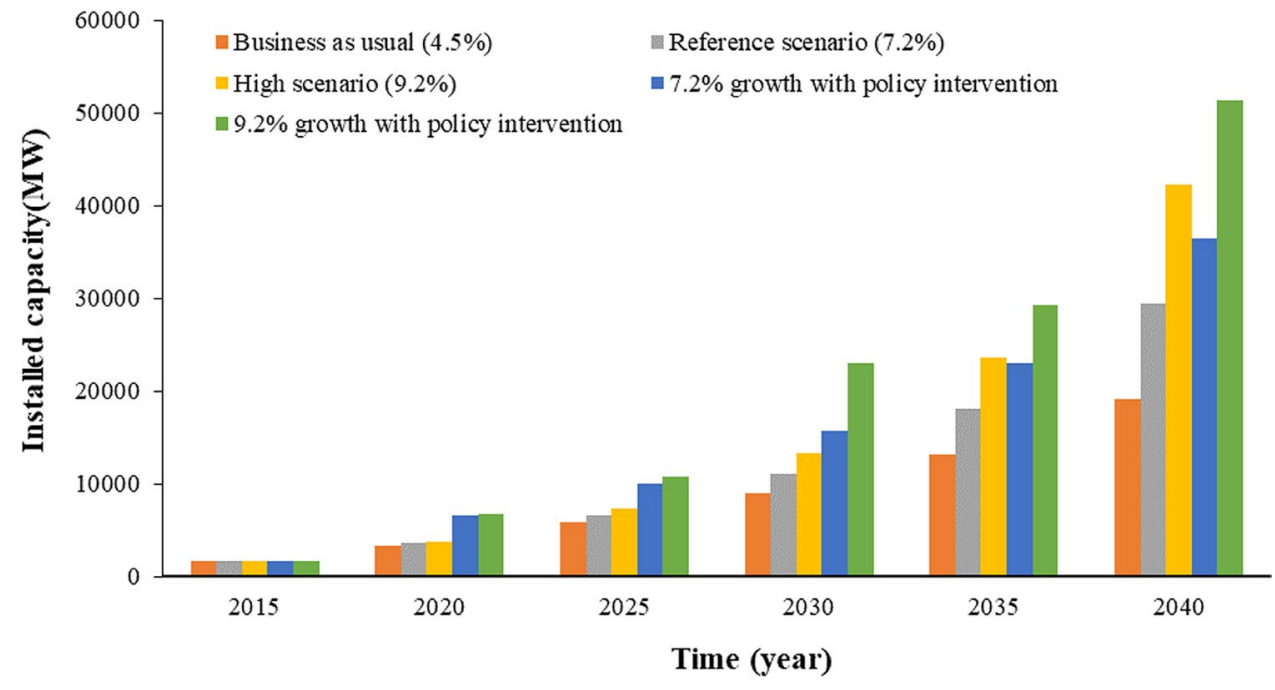

where imported oil products fully fulfill energy demand in the transport sector. Electricity shared only $0.06 \%$ of the final energy consumption of the transport sector, whereas oil products shared 99.94\% in 2017 (Zhou et al. 2020). 
To improve this situation, the Ministry of Physical Infrastructure and Transport, in association with the United Nations Center for Regional Development (UNCRD), has devised National Sustainable Transport Strategy (NSTS) with an insight to develop a transport system that is "efficient, accessible, people-centric, affordable, reliable, safe, inclusive, environmentally friendly, and climate and disaster-resilient" (Acharya et al. 2015). To mitigate climate change, Nepal's Nationally Determined Contribution (NDC) is a mechanism under Paris Climate Agreement 2015 in which it agrees to manage climate change and has four targets linked with the transport sector shown in Table 2. GoN has formulated and implemented several provisions and policies for electric mobility and the sustainability of transportation systems (GGGI 2018). By reducing the tax imposed on EVs, GoN has prioritized and published optimistic intentions to promote them.

\section{Rural electrification}

Because of rugged terrain and socioeconomic hindrance, the extension of the national grid line to rural areas has been challenging. Almost three-quarters $(72.84 \%)$ of total final energy consumption comes from traditional energy sources like firewood, agricultural waste, biofuel, etc., while electricity contributes only $3.66 \%$ in total consumption (IEA 2019). As per NEA, nearly $87 \%$ of households all over the country have electricity access through the national grid line. In rural areas not directly connected to the national grid, GoN, in association with Alternative Energy Promotion Centre (AEPC), has been providing electricity service through distributed sources like solar PV, wind, and micro-hydro power (MyRepublica 2020). However, those sources cannot resolve the rural electrification problem due to seasonal discrepancies in generation capacity and demand fluctuation. Those shortcomings can be overcome if distributed sources are integrated by establishing community-scale microgrids and hybrid power plants combining various available sources. Bhorleni village in Makwanpur district has a hybrid plant aggregated with 15 kilowatts $(\mathrm{kW})$ solar and $10 \mathrm{~kW}$ wind power, which supplies electricity to 131 houses at a minimal cost. Besides, a $12 \mathrm{~kW}$ solar-wind hybrid plant has been established in Dhaubadi Village of Nawalparasi district (Poudyal et al. 2019). Nepal has considerable potential for such distributed generation and hybrid system, shown in Table 3, which can contribute to filling the demand-supply gap of the village and the whole country if they are appropriately interconnected to the national grid line.

\section{Transition into smart grid}

It is fundamental to figure out the shortcomings of Nepal's existing transmission and distribution networks to assure a smooth transition into the smart grid. Figure 5 presents Nepal's power transmission network map with an existing and proposed network, reflecting the inhomogeneity of transmission networks distributed across the country. Major hydropower stations, the primary sources of electricity, lie in the Himalayan region due to abundant perennial rivers. However, the main load centers like industries, commercial zones, and large apartments lie far from generating stations

Table 2 Nationally determined contribution targets in addressing the transport sector in Nepal (GoN 2016)

\begin{tabular}{ll}
\hline Target & Description \\
\hline NDC Target 9 & To raise the percentage of EVs to $20 \%$ by 2020 , up from $10 \%$ in 2010 \\
NDC Target 10 & $\begin{array}{c}\text { To reduce reliance on fossil fuels in the transportation sector by } 50 \% \text { by } 2050 \text { via adequate mass public transporta- } \\
\text { tion and the promotion of energy-efficient EVs }\end{array}$ \\
NDC Target 11 & $\begin{array}{l}\text { To build an electrical (hydro-powered) rail network to enable mass commodities and public transportation by } 2040 \\
\text { NDC Target } 14\end{array}$ \\
& By 2025, to reduce air pollution by properly monitoring sources of pollution such as outdated and poorly main- \\
\end{tabular}

Table 3 Renewable sources with corresponding potential energy (AEPC 2008; Surendra et al. 2011)

\begin{tabular}{llll}
\hline Source & Technical potential & Economic potential & Remarks \\
\hline Major hydropower & $45,610 \mathrm{MW}$ & $42,133 \mathrm{MW}$ & Considering the major river basins \\
Mini-/micro-hydro & $>100 \mathrm{MW}$ & - & Viable in 55 districts \\
Concentrated solar power & $1829 \mathrm{MW}$ & - & $>4.5 \mathrm{kWh} / \mathrm{m}^{2} /$ day radiation and $2 \%$ country area \\
Grid-connected PV & $2100 \mathrm{MW}$ & - & $>4.5 \mathrm{kWh} / \mathrm{m}^{2} /$ day radiation and $2 \%$ country area \\
Wind & $3000 \mathrm{MW}$ & - & Assuming $10 \%$ area with more than $300 \mathrm{~W} / \mathrm{m}^{2}$ \\
Biofuels & 100,000 tons & - & Assuming $10 \%$ area with more than $300 \mathrm{~W} / \mathrm{m}^{2}$
\end{tabular}




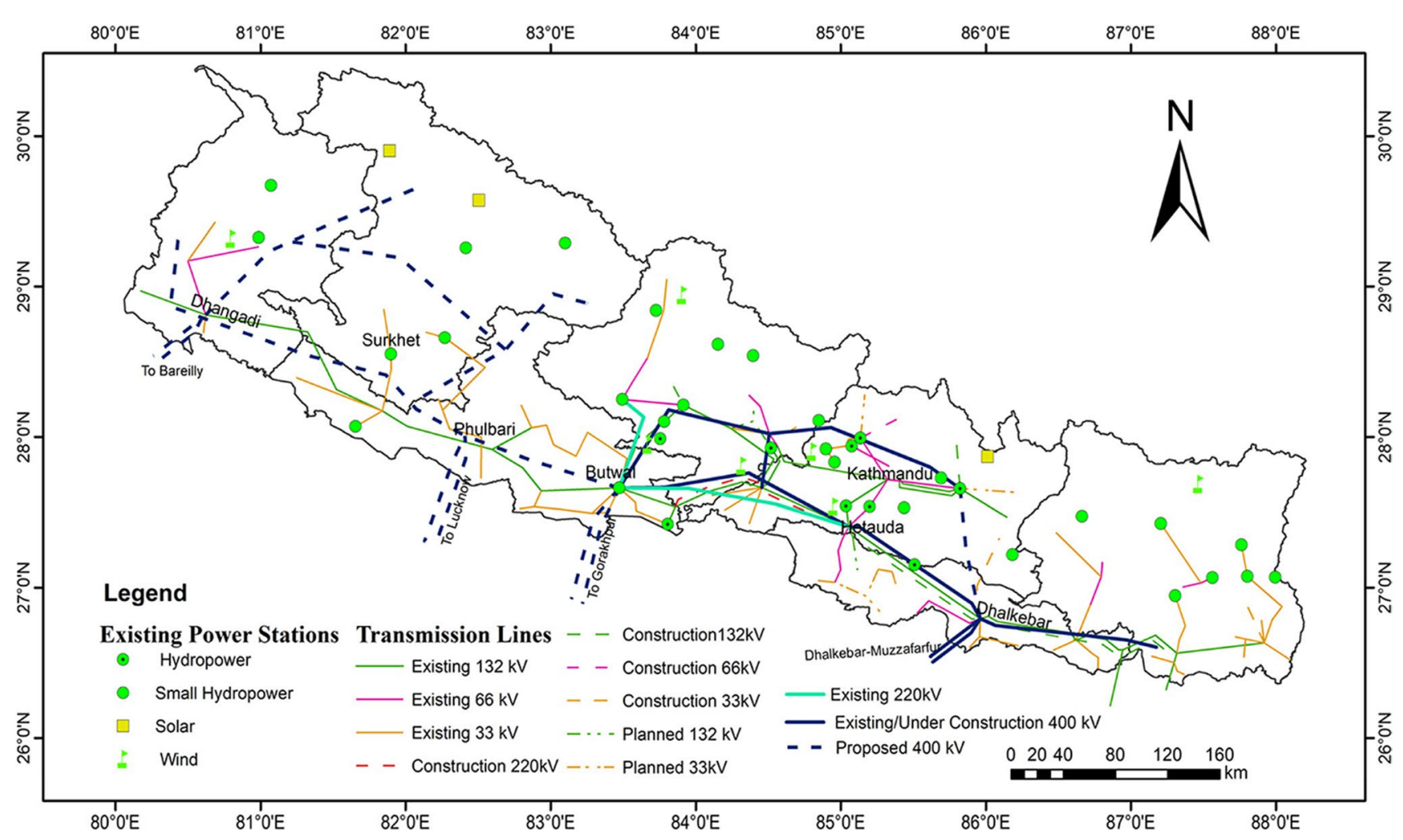

Fig. 5 Power transmission network map of Nepal, 2020 (Data Source: (The World Bank 2013; RPGCL 2020))

requiring longer transmission lines to fetch the required power. It is congested in commercial and industrial regions like $\mathrm{KaV}$, Butwal, and Hetauda, and scattered sparsely in other areas. About $75 \%$ of the long transmission lines, as of 2019 , operate at $132 \mathrm{kV}$. Only about $12 \%$ of transmission lines operate at $220 \mathrm{kV}$ or higher, resulting in transmission loss of $4.64 \%$, higher than the acceptable limit of about $2 \%$ (NACAA 2015). With the ever-increasing penetration of RESs and aging infrastructure, it becomes arduous to maintain grid stability and flexibility with existing transmission infrastructure. Moreover, an increase in the cost of acquiring high voltage transmission lines and disproportionate congestion areas due to lack of control also poses as restraints.

For transforming into a smart grid system, these issues need to be rectified by introducing Flexible AC Transmission System (FACTS) and Resilient AC Distribution System (RACDS) technology (Zhang et al. 2012). Some of the critical roles of FACTS and RACDS for transition into the smart grid in Nepal are illustrated in Fig. 6.
Fig. 6 Roles of FACTS and RACDS in transition into a smart grid in Nepal
FACTS

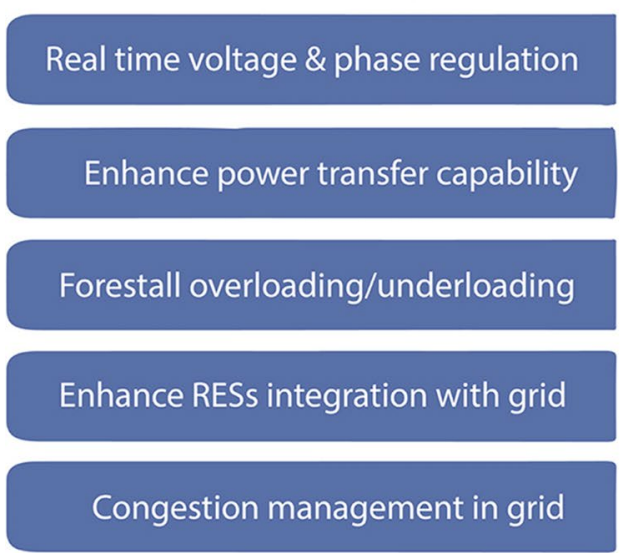

RACDS

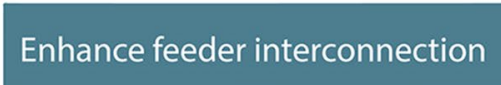

Reduce and regulate power outages

Facilate EV integration with grid

Enhance DG penetration in grid

Automatic load balancing and resilient distribution network 


\section{FACTS and its configuration}

The Institute of Electrical and Electronics Engineers (IEEE) has defined FACTS as "a power electronics-based system and other static equipment that provide control of one or more AC transmission system parameters to enhance control- liability and increase power transfer capability" (Edris et al. 1997). In the existing grid of Nepal, it is impossible to control different electrical parameters like impedance, phase angle, and magnitude of voltage in real time, which constrain the grid flexibility. But with FACTS devices and controllers, these parameters can be altered and composed in real time, offering a new level of opportunity for managing the network.

To control power flows, Nepal's AC grid system has been designed to incorporate mechanically switched series and shunt compensation along with voltage regulating components and phase-shifting transformers. To achieve a smooth transition into the smart grid, these components should be replaced by FACTS devices that use power semiconductors for quicker reaction to disturbance than mechanical systems. Static Var Compensator (SVC) and Thyristor Controlled Series Capacitor (TCSC) are conventional FACTS devices based on thyrist or switched capacitors and reactors. But the advancement of power electronics led to the invention of voltage source converters (VSCs) hinged on gate turn-off (GTO) and insulated gate bipolar transistor (IGBTS) ensure modern FACTS devices-static synchronous compensator (STATCOM) and unified power flow controller (UPFC). These devices can manage active and reactive power flowing in the grid at steady and transient stages by controlling parameters like voltages, phase angle, and impedance (AbuSiada 2017; Ghiasi 2019), reducing transmission losses and adding stability to the network.

To get assistance from FACTS, they need to be acquainted with the transmission network in specific configurations. Shunt compensation, series compensation, shunt-series configuration, and back-to-back configuration are different configurations of the FACTS devices in the smart grid. Peng and Wang (2019) discussed each configuration's role, functions, and limitations for maintaining grid stability, renewable energy integration, and power transferring efficiency. The same configurations are recommended for announcing FACTS in the transmission network of Nepal with adequate performance, economic, stability, and flexibility analysis. Table 4 presents commonly used FACTS devices with their functions and configurations, while Fig. 7 illustrates the transmission network with FACTS in the smart grid.

\section{RACDS and its configuration}

The architecture of the distribution network of Nepal is a primarily radial system, as shown in Fig. 8, due to which the entire feeder is interrupted in case of any faultsweather related or technical, and as a result, consumers connected to the whole feeder are unable to receive power. This underlines the fragility of the distribution system of Nepal, and therefore, transition into an intelligent grid is crucial to improve its resiliency. Similar to the FACTS, the concept to rejuvenate distribution system is summarized as RACDS, which enhances the resiliency of distribution system by engaging power electronics devices for distributed generation integration, voltage, and phase angle control to maintain a balance between active and reactive power and efficient load management (Peng and Wang 2019). Several studies and modeling analyses were performed worldwide, out of which integration of distributed generation, microgrid formation, and line hardening are the most common RACDS technology. Among them, microgrid configuration for enhancing resiliency, for its capability to incorporate distributed renewable sources and to operate in isolation, has been implemented most often in developed countries (Schneider et al. 2019).

Furthermore, the power grid can be made more resilient if locally generated and stored power from sole microgrids is conveyed to end-users via a distribution system for which they need to be incorporated into the distribution network (Abbey et al. 2014). Also, due to the intermittency of renewable sources, lively variation of voltage and frequency is another critical issue (Pourmousavi et al. 2012). To facilitate it, devices and controllers like FACTS are provided at the distribution level, referred to as controllable RACDS devices. In-depth RACDS devices and their configuration like FACTS are discussed in Ref. (Peng and Wang 2019). RACDS interconnected distribution network within a smart grid is illustrated in Fig. 9.

Table 4 Fundamental Information about FACTS controllers (Zhang et al. 2012; Gandoman et al. 2018)

\begin{tabular}{lllrr}
\hline Devices & Technology & Functions & $\begin{array}{r}\text { Configuration } \\
\text { Cost }(\$ / \\
\text { KVAR) }\end{array}$ \\
\hline SVC & Thyristor based & Regulate reactive power; control overvoltage; dampen power oscillation & Shunt & 35 \\
TCSC & Thyristor based & $\begin{array}{c}\text { Dynamically control line reactance; Improves transient stability of power system; } \\
\text { limit fault current }\end{array}$ & Series & 50 \\
STATCOM & VSC & Control under voltage; enhance power transfer capacity; improve power quality & Shunt & 40 \\
UPFC & VSC & Improve transient stability; dampen power oscillation; improve voltage stability & Shunt-series & 40 \\
\hline
\end{tabular}


Fig. 7 Schematic illustration of the transmission network in a smart grid (modified after (Peng and Wang 2019))
Fig. 8 Schematic illustration of a radial distribution network in Nepal
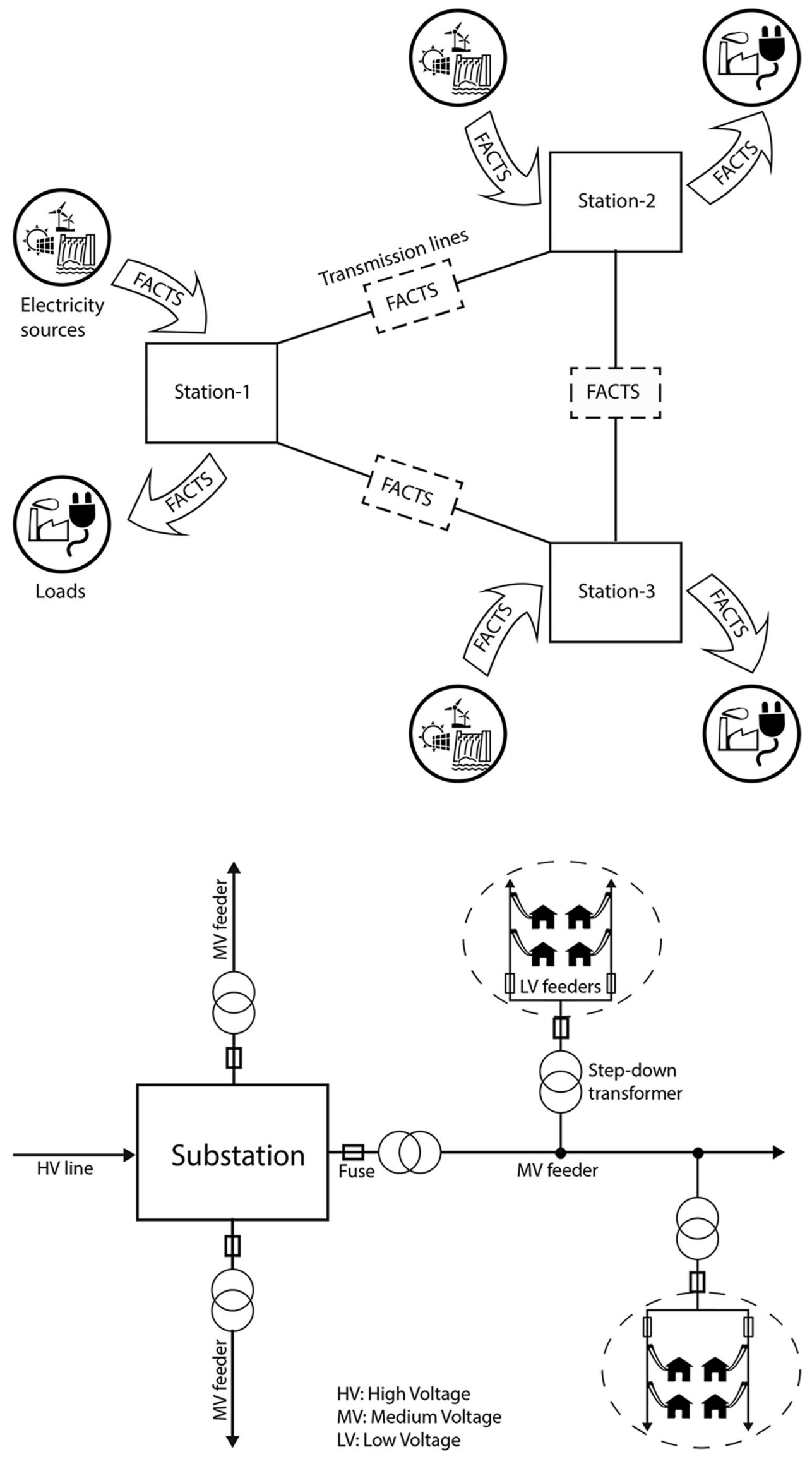
Fig. 9 Diagrammatic illustration of a distribution network in a smart grid (modified after Peng and Wang 2019)

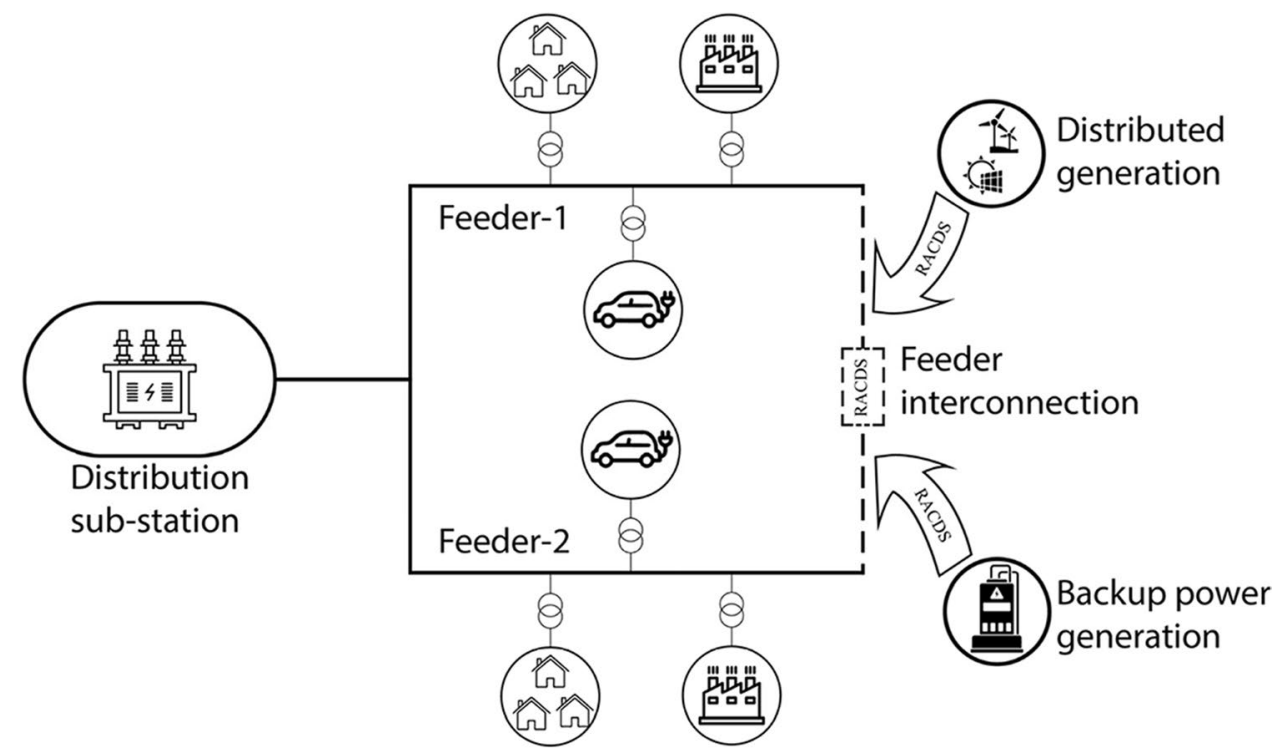

network utilization costs, equipment power losses, and insurance, which range from 1 to $5 \%$ of inception cost (L'Abbate et al. 2007). The cost of reliability is directly related to the cost of forced and unforced outages, i.e., benefits not accessible from the power system during outages. The cost of reliability may be determined by estimating this benefit, the average forced and unforced outage rate, and the time needed to return to service (Duarte 2020).

Furthermore, the cost of a specific FACTS device is dependent on device type and power rating, system voltage, administrative cost, ambient conditions such as temperature and pollution levels, and geography-specific physical limitations (Duarte 2020). Moreover, because of the need to import from other countries, their actual price in Nepal could be relatively high. The cost of conventional mechanically switched controllers ranges from US\$15 to 25 per
Fig. 10 Structure of inception cost for the application of FACTS devices

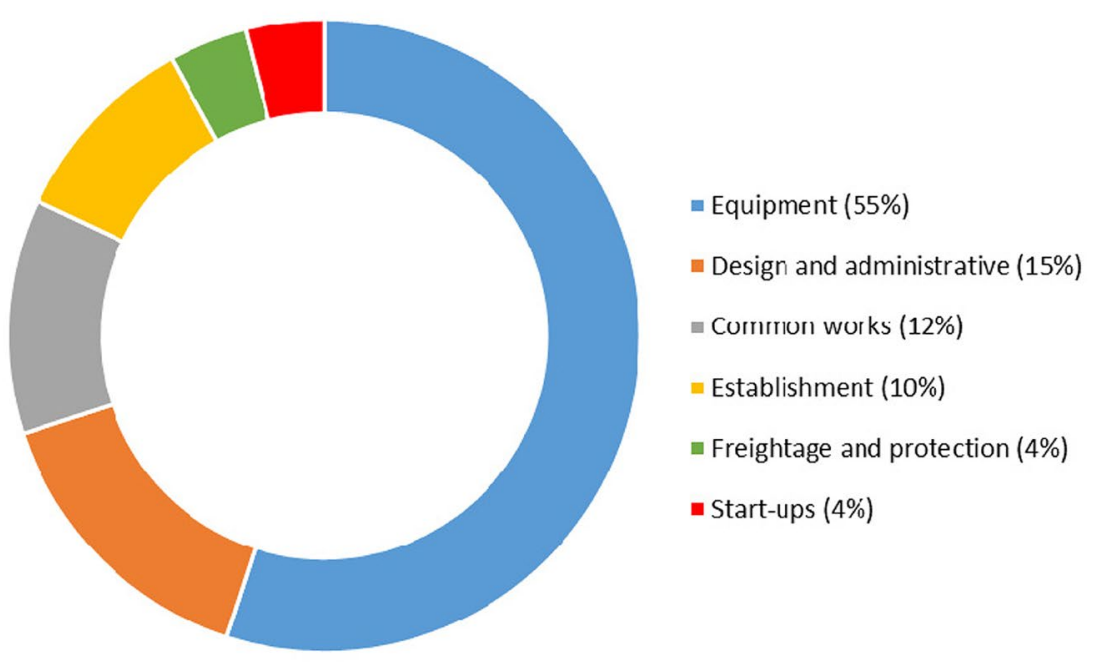


kilovolt-ampere reactive (KVAR) (Baldick and O'Neill 2009). Table 4 shows the average cost of some FACTS devices, and Table 5 provides the purchase and installation costs of various capacities (in megavolt-ampere reactive (MVAR)) FACTS devices (Gandoman et al. 2018). Therefore, FACTS controllers are more expensive than traditional mechanically switched control systems.

Blanco et al. has compared investment in traditional grid infrastructure with FACTS technology and suggests that the investments in FACTS are more efficient since they allow transmission grids to adapt to changing conditions (Blanco et al. 2011). In addition, FACTS enable economic distribution of produced electricity by enhancing capacity and better utilization of existing infrastructure while reducing losses and likelihood of fault occurrence. Thus, the installed FACTS controllers could be able to eliminate the need for new transmission lines, potentially saving a large amount of capital. Consequently, this will minimize the social and environmental impacts associated with the expansion of the transmission line (Acharya et al. 2005). Similarly, the costs and benefits associated with RACDS devices/controllers are comparable to that of FACTS. Therefore, the economic viability of implementing FACTS/RACDS technology in Nepal is justified by the technical merits, avoided monetary and non-monetary costs, and the possible direct and indirect advantages it provides in the energy and transportation sectors (Fig. 6). However, designers, operators, and utilities should undertake a rigorous financial and economic feasibility analysis before investing in FACTS/RACDS technology to develop a sustainable and efficient power grid.

\section{Smart microgrid}

Microgrids are small electrical networks that can be operated in isolated mode or grid-connected mode and have their storage units, whose size and capacity depend upon the extent of integrated distributed generation (Adefarati and Bansal 2017). In Nepal, several micro-grids comprising distributed renewable resources like micro-hydro, solar PV, and wind turbines are under operation in rural areas where the national grid line has not been reached yet. For example: Urja Upatkya Minigrid (107 kW) in Baglung, Thingan Minigrid $(28 \mathrm{~kW})$ in Makwanpur, solar-wind hybrid minigrid $(35 \mathrm{~kW})$ in Sindhuli etc. The various technical and management issues experienced by existing microgrids in Nepal are illustrated in Fig. 11.

Smart grid components can fix these issues, thus transforming them into smart microgrids by introducing smart technologies like energy storage devices, advanced metering infrastructure (AMI), smart appliances, computational intelligence, active demand response management, and the Internet of Things (IoT).

The rise in the integration of variable renewable sources makes energy storage devices an indispensable part of microgrids. The energy storage system improves the quality,
Table 5 Price of some FACTS devices (Gandoman et al. 2018)

Fig. 11 Issues associated with the existing microgrids in Nepal (Shrestha et al. 2019)

\begin{tabular}{llllll}
\hline Cost (\$/KVAR) & & & & & $\begin{array}{l}\text { Installa- } \\
\text { tion cost } \\
\text { included }\end{array}$ \\
\hline Type & 100 MVAR & 200 MVAR & 300 MVAR & 400 MVAR & No \\
\hline SVC & 60 & 50 & 45 & 40 & Yes \\
& 100 & 80 & 70 & 60 & No \\
STATCOM & 90 & 75 & 68 & 60 & Yes \\
& 130 & 115 & 110 & 100 & \\
\hline
\end{tabular}

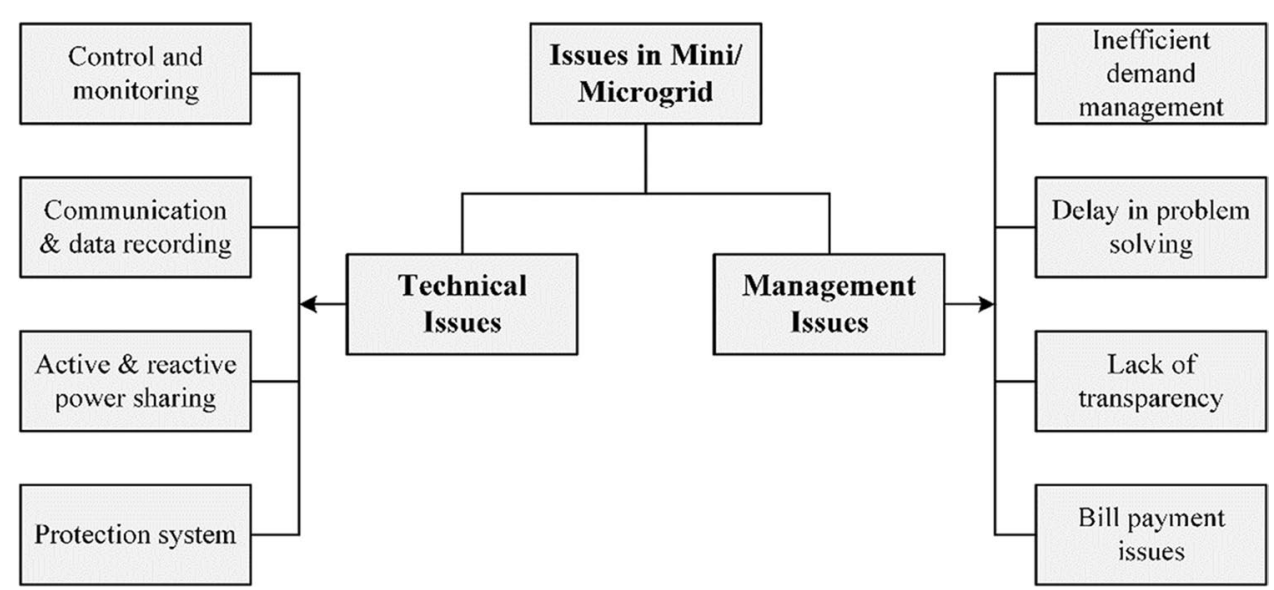


reliability, and balancing of power in the grid and allows energy storage during non-peak hours and discharging during peak hours (Spataru and Bouffaron 2016). The disposition and incorporation of energy storage techniques like the flywheel, supercapacitors, advanced battery technology, and pumped hydro storage has provided a broad vision for smart microgrids (Abdi et al. 2017). AMI allows technology such as smart meters to facilitate a two-way exchange of information between consumers and utilities (Balakrishna and Swarup 2020). This would provide microgrids with a wide variety of capabilities, such as remote consumption control, time-based pricing, demand forecasting, theft and loss detection, and efficient revenue collection. Also, smart appliances or loads that allow two-way information flows with the grid improve power quality and reliability (Yan et al. 2017b). Various statistical and artificial intelligence methods for advanced forecasting of demand and variable RESs are crucial for smart microgrids to develop strategies for reducing the demand-supply gap and active demand response management (Yoldaş et al. 2017). With an increase in penetration of many distributed energy resources and interconnection of loads in microgrids, IoT solves the energy management, security, and power quality issue popup due to the increase in penetration of distributed energy resources and interconnected loads in smart microgrids (Birleanu and Bizon 2020). Furthermore, with the aid of these smart characteristics, the substantial reliability of EV charging stations can be achieved by efficiently and economically integrating them with community-scale microgrids, as discussed in Ahmad et al. (2019).

With the advent of smart features mentioned above, active demand response management can be achieved in the smart microgrids, thereby shifting peak load to an off-peak hour, reducing the undesired power outages, lowering the energy production cost, and bettering the power quality. Also, utilizing abundant distributed renewable resources with proper planning, study, and analysis, several such smart microgrids can be established in remote and urban areas of Nepal. Consequently, these smart microgrids can be integrated with the national grid to form a large-scale smart grid, thus making it flexible, resilient, reliable, and energy-efficient.

\section{Electric vehicle in smart grid}

Nepal has experience of running EV technology like trolleybuses and electric three-wheelers named "Safa Tempos" inside the KaV since the 1970s and 1990s, respectively. The trolley bus operation was terminated in 2011; however, Safa Tempos are still providing their service inside the $\mathrm{KaV}$ (GoN 2018b). Despite having an early start, Nepal has been unable to make any significant progress in electrifying the transport sector due to several barriers as discussed in
Table 6. Many studies recommend some feasible solutions to overcome these hurdles; nevertheless, various practical factors may make implementation difficult (Table 6). Nepal is a landlocked country, and the country's harsh topography has made expanding the road network challenging. As a result, the requirement to import the bulk of materials and components, particularly without access to the cheapest form of transportation, namely, water transport, has stifled local industrial growth. In addition, several necessary mineral resources, such as lithium, iron, cobalt, nickel etc., have not been explored due to a lack of capital and technology (Paudel 2019). Furthermore, because the majority of remote areas lack access to roads and energy, the current distribution of EVs across the country is not uniform and concentrated in cities; for instance, Safa Tempos operate in KaV. Aside from these practical challenges, the GoN and relevant authorities have initiated some efforts to promote the transition to EVs, and the present state is included in Table 6. Moreover, the proposed initiatives/solutions for overcoming the barriers can be executed systematically and methodically by following the roadmap or framework depicted in Fig. 12.

Electric vehicles present both obstacles and opportunities for the power systems of Nepal. If charging activities co-occur with current consumption peaks, the possibility for increased peak energy demand may entail due to substantial EVs penetration. The uncontrolled charging of large-scale EVs results in significant voltage drop, overloading, and power loss in the distribution system (Luo et al. 2013). To alleviate these issues, one of the possible measures is to employ EVs as flexible/dynamic loads that can offer balancing services to networks with a high proportion of varying renewable energy supply (Kempton and Letendre 1997; Bibak and Tekiner-Moğulkoç 2021). To fully realize EVs' capability as a flexible or dynamic load, smart charging procedures must be employed.

\section{Smart charging}

Smart charging can occur in a centralized manner through aggregators or decentralized manner through decentralized control structures. In a centralized control structure, the optimal scheduling of each EV is handled by an aggregator. At the same time, in a decentralized system, each electric vehicle chooses its charging method without contacting the central controller or other linked EVs (Galus et al. 2013). In comparison to uncontrolled charging, both the centralized and decentralized systems may successfully decrease the energy costs and prevent the overloading of grid components by shifting peak demand to off-peak hours (Vaya and Andersson 2012; Patil and Kalkhambkar 2020). Although the centralized approach is more reliable and accurate and provides a more significant reduction in the GHG emission (Cheng et al. 2018), the scalability issues, the necessity for 


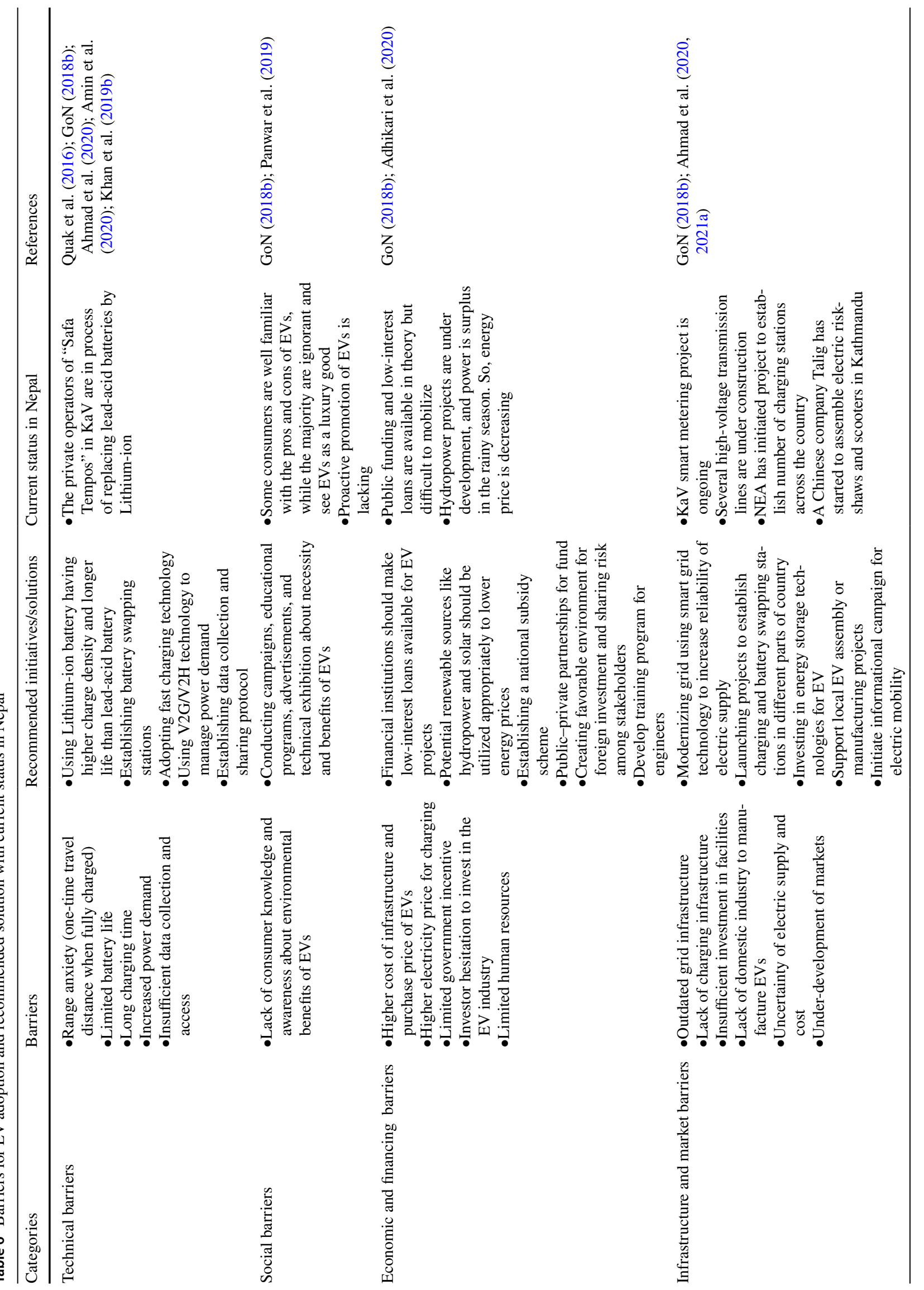




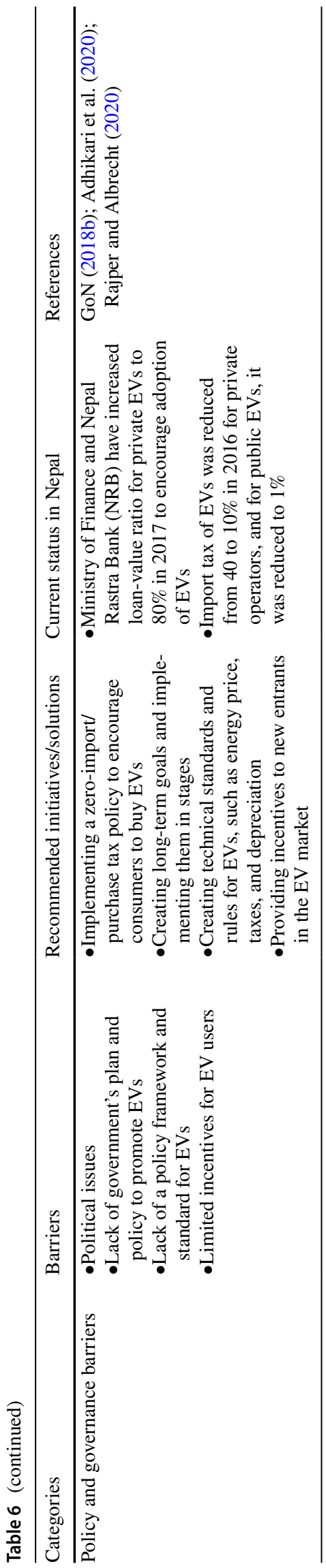

effective real-time bi-directional communications, high cost of implementation, and lack of privacy protection (Vaya and Andersson 2012) can pose restraints for its performance in the context of Nepal. But, in a decentralized system, EV users can plan their charging strategy and avoid the issues mentioned earlier to a greater extent (Xu et al. 2019). Both strategies have their pros and cons; however, in decentralized strategy, the quick convergence of optimization problem requires low computational efforts and provides greater efficiency, which indirectly lowers the cost of equipment (Jian et al. 2017; Xu et al. 2019; Liao et al. 2021). So, from cost-benefit perspective, the decentralized strategy appears to be a more feasible system for Nepal, which is in the early phase of EV development. Furthermore, to reap the benefits of the smart charging approach, EV charging stations should be strategically positioned in the distribution network of the power grid following the enhanced approach as discussed in Ahmad et al. (2021b). Nonetheless, before implementation, a detailed study is required to determine whether a particular charging strategy is appropriate for a specific region.

\section{V2X technology}

In a smart grid, when linked to the power grid for charging/discharging, EVs are referred to as grid-connected EVs (GEVs). With the plug-in feature, these GEVs can draw energy from the power grid and provide it back to the grid via the bidirectional charger. Depending upon the charging/discharging potential of GEVs and the energy-efficient needs of the power grid, vehicle-to-home $(\mathrm{V} 2 \mathrm{H})$, vehicle-tovehicle (V2V), and vehicle-to-grid (V2G) concepts (Fig. 13) have grown increasingly appealing. These smart technologies allow GEVs to function as vehicles and flexible, controlled loads and distributed energy sources for the power grid (Liu et al. 2013). Extensive research activities have been conducted to optimize the cost and performance of V2X technology, making it economically and technically feasible (Khan et al. 2018b).

According to NEA, peak electricity demand occurs between 5 p.m. and 11 p.m., and in the same period, most of the vehicles, both public and private, are parked either in homes or stations. In such a scenario, V2H technology allows users to connect several vehicles to an electricity distribution board of home and makes it possible to meet demand at night time. And, the exact vehicle can be changed later from the power grid during off-peak hours or by intermittent renewable sources like rooftop solar PV (Khan et al. 2018a; Shariff et al. 2020). Also, with the advent of V2G technology, EVs may be clustered via aggregator to offer grid services such as load leveling, peak shaving, and voltage regulation at a lower cost and with less environmental effects than present systems. Therefore, with the deployment of smart grid technology, EVs will operate effectively and 
Fig. 12 Policy roadmap/framework for implementing recommended solutions against EVs barriers (GGGI 2018)
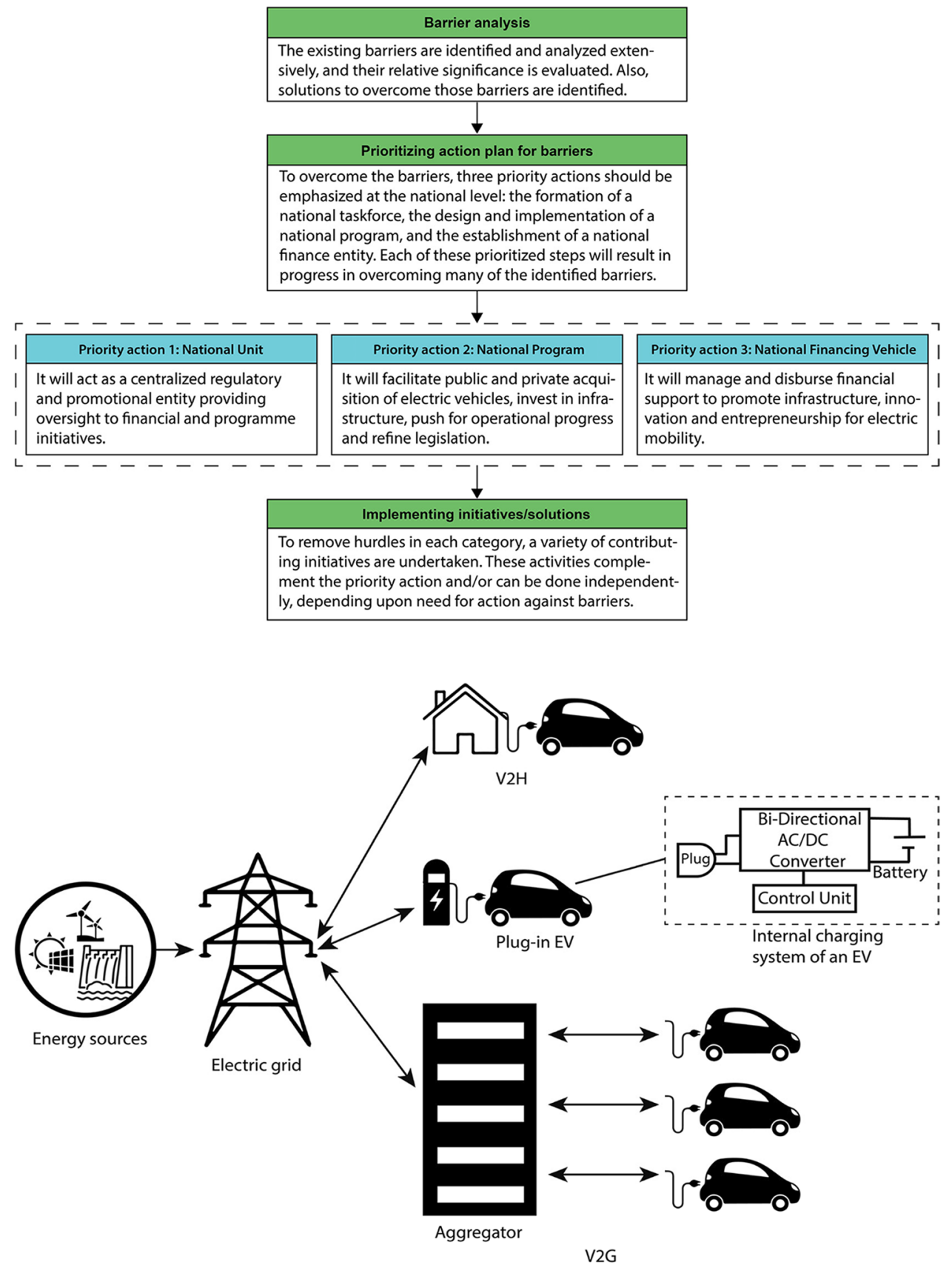

Fig. 13 Electric vehicle concept (V2G and V2H) in a smart grid (modified after Khan et al. 2019a) in a controlled manner benefiting all the stakeholders associated with it, thus accelerating the growth of EVs in the Nepalese transport industry.

\section{Best practices for deployment of EV charging infrastructure}

Energy and charging infrastructure is one of the most crucial components for EV acquisition globally, and utilities are focusing their expertise and resources on infrastructure deployment (Bolduc et al. 2020). According to Adhikari et al., infrastructural obstacles are the most significant impediments to EV adoption in Nepal (Adhikari et al. 2020). Thus, the utility sector of Nepal must adopt best practices to develop a charging infrastructure network that is both effective and efficient. Furthermore, if utilities devote their resources to $\mathrm{EV}$ charging infrastructure following best practices, they can produce considerable revenue now or shortly.

EV charging infrastructure should be strategically positioned with careful planning to maximize the usage of existing energy infrastructure while also ensuring that the location is suitable as per the need of users (Hildermeier et al. 2019). To minimize the under-utilization of charging infrastructure, it is vital to determine the density of charging equipment through 
accurate monitoring of users' charging and driving patterns (Helmus et al. 2018). A report by Smart Electric Power Alliance (SEPA) has discussed the utility-led and third-party EV infrastructure initiative best practices in the US that will aid the utility to develop a successful EV program (Bolduc et al. 2020). While multiple similar options exist for shaping EV charging infrastructure programs in Nepal, their effective execution needs to follow critical steps, as outlined in Table 7. Table 7 also demonstrates best practices shared by successful utilities in the US EV industry; therefore, utilities in Nepal and other developing countries should follow similar practices.

\section{Opportunities for WWTPs in smart grid}

Peaking urbanization has adversely affected the water and sanitation sector, resulting in increased wastewater production across Nepal, particularly in highly urbanized and densely inhabited cities like KaV. However, due to poor planning and sluggish development of treatment facilities, it is recognized to have one of the worst wastewater treatment facilities in the Asia-Pacific region (UNESCO 2017). The bulk of existing centralized WWTPs partially function in urban areas like $\mathrm{KaV}$, while rural areas do not have access to them (GoN 2015). One of the main reasons for their poor performance is the inability of the energy system to satisfy their demand (Regmi 2013). Such WWTPs are projected to consume about 30 TWh energy yearly (its breakdown presented in Fig. 14) which may constitute more than $40 \%$ of a WWTP's annual operating cost (Lemar and De Fontaine 2017).

For remote areas, decentralized WWTPs like constructed wetlands are considered feasible, cost-effective, environmentally friendly, and sustainable solutions, but constant energy supply is crucial to ensure their practical functionality (Jha and Bajracharya 2014). Since there is an unreliable power

Table 7 Key steps for EVs infrastructure development program with best practices (Bolduc et al. 2020)

\begin{tabular}{|c|c|c|}
\hline Steps & Objectives & Best practices \\
\hline Planning & $\begin{array}{l}\text { To offer a satisfying customer experience, a } \\
\text { significant amount of time and effort should be } \\
\text { dedicated to the planning phase }\end{array}$ & $\begin{array}{l}\text { Identification of target customers and the number of } \\
\text { charging stations required; identification and evalu- } \\
\text { ation of potential sites; determination of customer } \\
\text { requirements; establishing quality control process; } \\
\text { employee training programs; creating a roadmap } \\
\text { for the program; load management strategies; } \\
\text { approving charging equipment that meet safety and } \\
\text { functional requirements; establishing a process for } \\
\text { maintenance of charging infrastructure }\end{array}$ \\
\hline Customer engagement & $\begin{array}{l}\text { To maximize utility's program budget for marketing } \\
\text { and minimize delays }\end{array}$ & $\begin{array}{l}\text { Developing and launching marketing and customer } \\
\text { engagement strategies to targeted customers; } \\
\text { providing transparency about the program progress; } \\
\text { updating customers with change; aware EV manu- } \\
\text { facturers about the program; coordinating with city } \\
\text { leadership and decision-makers; helping communi- } \\
\text { ties understand EV technology; being aware of any } \\
\text { EV-related incentives and policies by the govern- } \\
\text { ment }\end{array}$ \\
\hline Evaluation & $\begin{array}{l}\text { To assess overall feasibility and finalize a detailed } \\
\text { implementation plan }\end{array}$ & $\begin{array}{l}\text { Performing high-quality reviews of each potential site } \\
\text { before engaging a design firm; standardizing crite- } \\
\text { ria for site design; recommending design based on } \\
\text { data (number and type of vehicles, charging time, } \\
\text { location, etc.); anticipating customers' plans }\end{array}$ \\
\hline Design and construction & $\begin{array}{l}\text { To construct charging infrastructure according to } \\
\text { plan }\end{array}$ & $\begin{array}{l}\text { Considering a service drop from customer trans- } \\
\text { former as far as possible; coordinating with authori- } \\
\text { ties having jurisdiction to reduce time and cost } \\
\text { linked with the permit and plan checks; engaging } \\
\text { closely with final site commencing to ensure all } \\
\text { components are installed safely; making provisions } \\
\text { for future deployment of additional infrastructures }\end{array}$ \\
\hline Customer and regulatory follow-up & To continuously improve utility's program & $\begin{array}{l}\text { Surveying customers to determine satisfaction; filing } \\
\text { regulatory reports; organizing advisory meetings } \\
\text { with stakeholders; publishing results and finding } \\
\text { of projects; making aggregated customers charging } \\
\text { data freely available; learning to better design and } \\
\text { enhance next EV program }\end{array}$ \\
\hline
\end{tabular}


Fig. 14 Energy breakdown of various components of a typical WWTP (data source: Lemar and De Fontaine 2017)

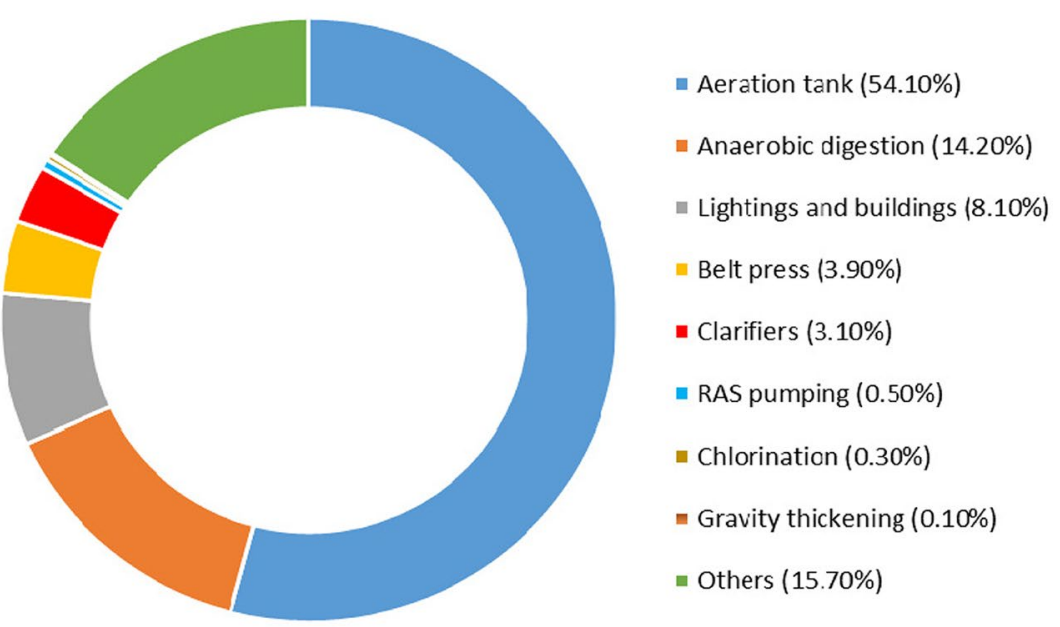

supply in rural areas of Nepal, the reliability of such decentralized WWTPs is questionable.

Making self-sufficient WWTPs by utilizing accessible RESs like biomass, microbial fuel cells, and solar PV is one viable option for maintaining power supply dependability and making WWTPs work efficiently (Quintero Pulido et al. 2018). A net-zero energy wastewater treatment concept (Fig. 15), based on biomass power recycling, was developed to reduce resource waste and enhance energy recycling in wastewater treatment plants (Yan et al. 2017a). This requires an appropriate storage system, appropriate technology for voltage and frequency management, and efficient connectivity to an external power supply. Furthermore, adequate energy forecasting technology is required to anticipate the amount of recovered energy for efficient demand response management inside WWTPs. As a result, smart grid technology has become an essential foundation for building net-zero energy/self-sufficient WWTPs (Moazeni and Khazaei 2021).

Several studies have highlighted the potential of WWTPs to produce biogas, thermal energy, and other biochemical derivatives that can be converted into electricity via a variety of methods, including (a) anaerobic fermentation of separated sludge and conversion of biogas to electricity, (b) combustion of separated sludge and conversion of heat to power, and (c) integration in the water treatment process of microbial fuel cells (Mamut and Badea 2015). Recent research in Nepal found that the entire biogas potential from the projected 200 MLD wastewater in $\mathrm{KaV}$, with an average COD content of $1000 \pm 225 \mathrm{mg} / \mathrm{L}$, is estimated to be $23,105 \pm 5185 \mathrm{Nm}^{3} /$ day, corresponding to a total energy potential of $3.35 \pm 0.76 \mathrm{MW}$ (Ramtel et al. 2021). With the introduction of smart grid technology, opportunities will
Fig. 15 Net-zero energy concept in WWTPs ( adapted from Yan et al. 2017a)

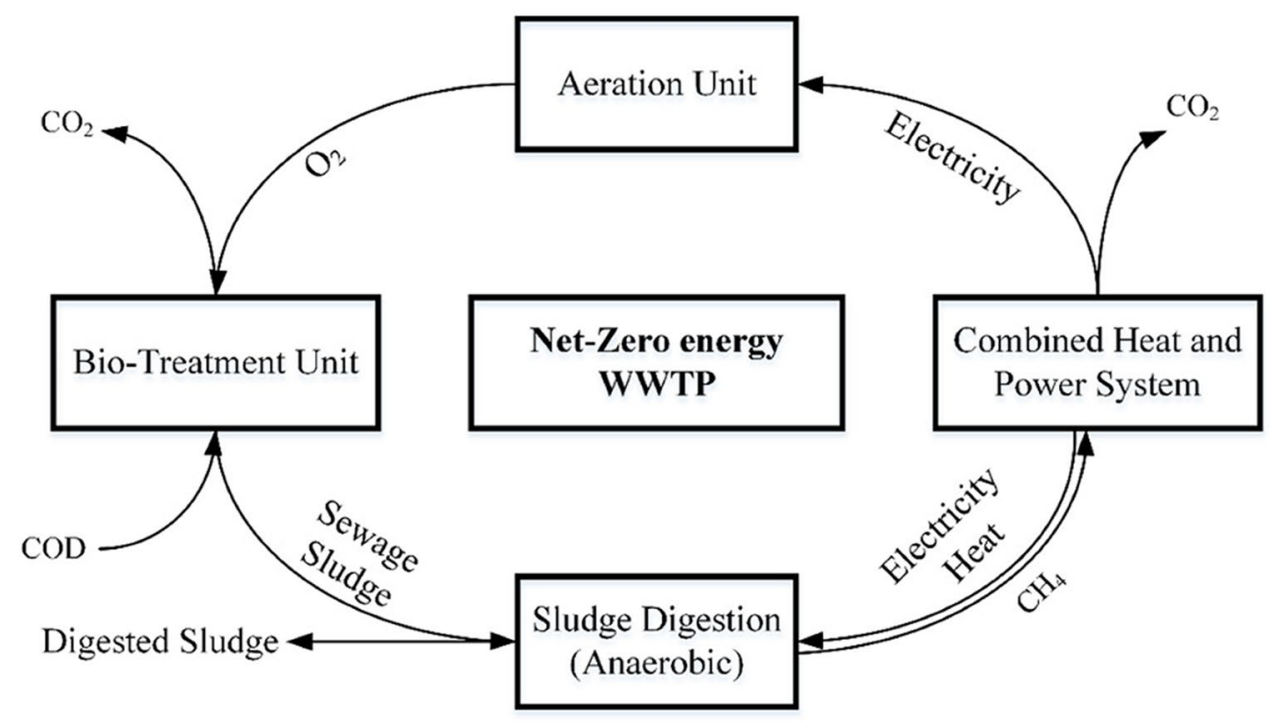


arise to harness the potential bioenergy present in centralized and decentralized WWTPs around the country, allowing them to become energy self-sufficient and excess energy to be incorporated into the national grid line.

\section{Challenges of smart grid implementation in Nepal}

Smart grids employ cutting-edge technology to address current complexities in Nepal's traditional electricity networks while also providing a plethora of chances to improve their efficiency and reliability. However, its implementation is hindered by the several technical and socioeconomic challenges summarized in Fig. 16.

Nepal's present grid infrastructure is insufficient to meet expected renewable energy integration and response management demands, posing several smart grid designs, building, operation, and maintenance issues. The frequent and intermittent variation of active power supplied by integrated renewable energy sources causes significant voltage variance at the distribution level. Existing grid voltage regulators, such as tap changers and capacitor tanks, cannot correct rapid fluctuations caused by these sources. As a result, power electronics technologies like FACTS and RACDS, efficient energy storage systems, and other smart technology must be incorporated to ensure voltage and frequency stability in the grid (Fallahzadeh-Abarghouei et al. 2018; Firouzjah et al. 2019). However, smart infrastructures such as smart meters, energy storage systems, FACTS, database

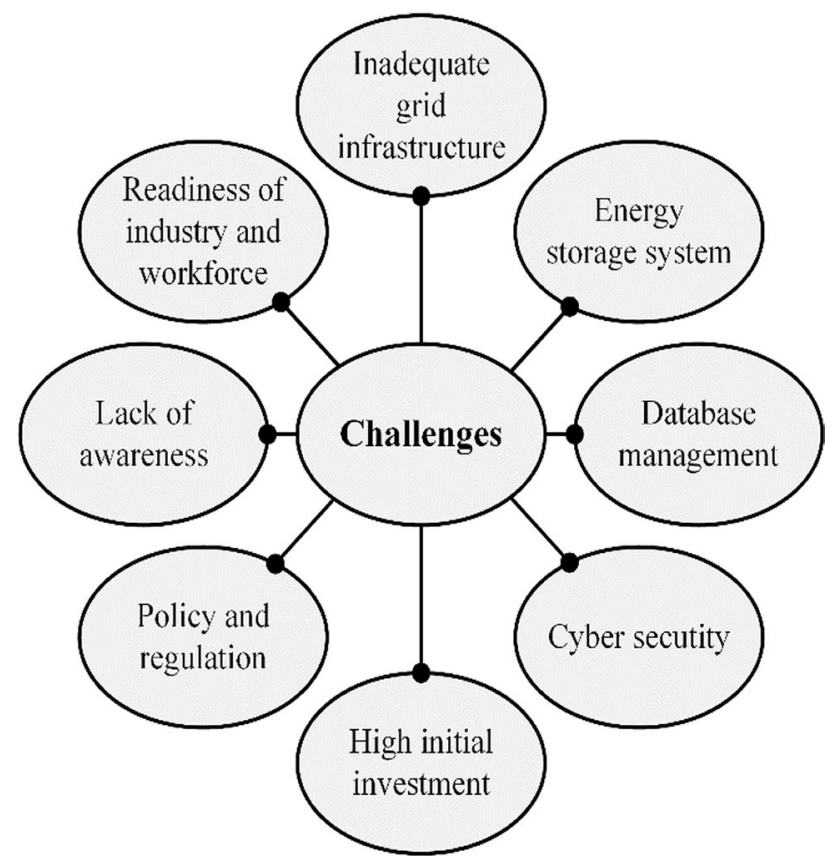

Fig. 16 Major challenges associated with the application of a smart grid in Nepal management, communication systems, etc. require sizeable initial investment (EPRI 2011). The availability of funding is thus a key barrier to establishing a smart grid in Nepal.

In addition, there are no well-defined rules or guidelines in Nepal to govern smart grid efforts. The majority of present legal and regulatory frameworks were created to address existing networks and utilities. As a result, current legislative and regulatory frameworks will need to be amended to facilitate the deployment of smart grids. The new framework must be designed to maximize contributions from all sectors, and all stakeholders-government, utilities/investors, and consumers - share the potential risks. Therefore, new regulations and policies must consider the following aspects (Kappagantu and Daniel 2018):

- Investment to be shared among consumers, utilities/ investors, and the government

- Incentives for the adoption of renewable energy technology

- Reducing the tax levied on EVs and renewable energy technologies

- Create action plans and norms

- Meet all stakeholders' expectations, particularly those of consumers

- A genuine emphasis on workforce development and public awareness campaigns

Utilities in smart grids have a significant data management challenge since a considerable quantity of data is generated. As a result, processing and storing huge volumes of data exchanged among multiple smart grid components need a secure processing and storage facility. Otherwise, hackers and viruses can get unauthorized access to data and leak it, posing a severe threat to users' privacy and confidentiality (Tu et al. 2017). So, database management and cyber security are significant challenges to address while adopting smart grid technologies.

Another obstacle to establishing a smart grid strategy in Nepal can be a lack of consumer understanding about the smart grid. As a result, consumers should be educated about the concept of a smart grid, its role in the transition to carbon-free energy, and its advantages for them. They must also be taught about their energy usage habits, allowing them to participate actively in demand response management and become prosumers (producer+consumer) rather than simply consumers. Furthermore, authorities and regulators must have a comprehensive understanding of the smart grid's future potential, and utilities must concentrate on fully exploiting its capabilities.

\section{Conclusions and policy implications}

We reviewed the current scenario, explored the needs, and presented various opportunities that developing countries like Nepal can undertake by implementing smart 
grid technologies. Through these technologies, Nepal can increase the share of renewable energy usage to address current and future energy problems and contribute toward the global sustainable development goal.

The semiconductor-based FACTS and RACDS devices, by replacing current mechanically-driven devices, will make the system more responsive during faults, and energy losses will be reduced. Similarly, a smart grid will provide a huge opportunity to alleviate the rural electrification problem by widely implementing smart microgrids built on plentiful RESs such as solar PV, wind, and biomass, engaging the private business and connecting them to the national grid. Similarly, smart and scheduled charging of EVs in a smart grid environment will encourage people to embrace EV technology; therefore, vehicular emissions and dependence on fossil fuel will be reduced significantly. EV concepts such as V2H and V2G will enable EVs to be utilized as both an energy supplier and a load, making them essential partakers in demand response management. Furthermore, by capturing, regulating, and controlling their potential biomass energy, the smart grid will assist WWTPs throughout the country to become energy self-sufficient.

Although smart grids provide a broad range of opportunities for power sector reform in Nepal, several technical and socioeconomic challenges may make their implementation difficult. These issues can be addressed if the GoN and NEA jointly adopt policies and strategies that promote their development. The results of existing smart grid initiatives like the Kathmandu Valley Smart Metering Project, on the other hand, can offer insight into how its development will proceed in Nepal.

The findings of this study imply that several components of smart grid technology are in a trend of progressive deployment in the country as a result of new initiatives, policies, and frameworks implemented by the government and related authorities in recent years. Also, this paper concludes that there is a significant potential of this technology in Nepal's energy sector for the effective and efficient utilization of vast RESs, better energy management, environmental protection, and overall socioeconomic progress; however, there is a significant gap between current degree of achievements and the potential available. The following policy-related suggestions are proposed based on the findings of this study. First, government and other national authorities should make policies and frameworks that support and prioritize the investment in RETs. In this regard, a stable political environment is necessary to assure the safety of investment of domestic and foreign investors. Also, the government should proactively promote the research and development activities to identify the issues concerning the time and budget overrun of national-level hydropower projects to avoid similar complications in the future. These policies should be designed optimally to reinforce the other climate change-related policies. Second, utilities should pursue digitalization, which provides a significant opportunity to minimize grid losses, energy theft, timely fault detection, and operational expenses. Digital media makes it easier for customers to analyze and manage their energy usage patterns, reduce energy waste, and support demand-side management. Third, the increasing necessity for grid restructuring demands decentralized the power system control. Currently, NEA is the centralized government entity that monitors the planning, execution, and operations of projects and initiatives related to different components of the power system. With a large number of distributed RESs generating energy in near future, it will be difficult to manage centrally. Therefore, for Nepal's energy sector seeking resiliency, reliability, and flexibility, a decentralized control system might be a new paradigm.

In essence, policymakers in developing countries like Nepal should promote the smart grid approach to minimize energy loss, lower energy costs, utilize clean energy, and improve power system reliability and management. This will also result in new employment opportunities, which will help the country's overall socio-economic growth. In a broader sense, the advent of smart grid technologies will not only serve as a solution to existing energy-related problems across developing countries but will also reduce global carbon footprint and contribute to the achievement of global sustainable energy goals, and thus lessen the impacts of global climate change in the years to come.

Acknowledgements The authors like to acknowledge collaborative organizations/institutions: Tribhuvan University, Institute of Engineering, Pulchowk Campus, Nepal; Tarbiat Modares University (TMU), Iran; School of Engineering and Mathematical Science, La Trobe University, Australia; Federal University of Fronteira Sul, Erechim, Brazil. The corresponding author is responsible mainly for all kinds of expenses during this study. The authors like to extend sincere gratitude to the anonymous reviewers for their critical comments, which enhance the manuscript quality.

Author contribution Writing an original draft, visualization, literature review, editing: Tek Narayan Bhattarai; validation, Literature review, writing-review, and editing: Swastik Ghimire; validation, writingreview, and editing: Bandita Mainali; writing-review and editing: Shiva Gorjian; writing-review and editing: Helen Treichel; conceptualization, supervision, writing-review and editing: Shukra Raj Paudel.

Availability of data and materials Not applicable.

\section{Declarations}

Ethical approval Not applicable.

Consent to participate Not applicable.

Consent for publication Not applicable.

Competing interests The authors declare no competing interests. 


\section{References}

Abbey C, Cornforth D, Hatziargyriou N et al (2014) Powering through the storm: microgrids operation for more efficient disaster recovery. IEEE Power Energy Mag. https://doi.org/10.1109/MPE. 2014.2301514

Abdi H, Mohammadi-ivatloo B, Javadi S et al (2017) Energy storage systems. Distrib Gener Syst Des Oper Grid Integr 333:368. https://doi.org/10.1016/B978-0-12-804208-3.00007-8

Abu-Siada A (2017) Review of flexible AC transmission systems; enabling technologies for future smart grids. Int Conf High Volt Eng Power Syst ICHVEPS 2017 - Proceeding 2017-January: 6-11. https://doi.org/10.1109/ICHVEPS.2017.8225856

Acharya N, Sode-Yome A, Mithulananthan N (2005) Facts about flexible AC transmission systems (FACTS) controllers: practical installations and benefits. Aust Univ Power Eng Conf (AUPEC), AUPEC-2005 1-7

Acharya SR, Pande K, Batthan G, Earley R (2015) National Sustainable Transport Strategy (NSTS) for Nepal (2015-2040). Nagoya. .https://www.uncrd.or.jp/content/documents/3377Background Paper -EST Plenary Session 2 (No. 1).pdf

ADB (2018) Smart metering roadmap for Nepal. Mandaluyong. https:// doi.org/10.1201/b11300-4

ADB (2017) Nepal energy sector assessment, strategy, and roadmap. Mandaluyong. https://doi.org/10.22617/TCS178936-2

Adefarati T, Bansal RC (2017) Reliability and economic assessment of a microgrid power system with the integration of renewable energy resources. Appl Energy 206:911-933. https://doi.org/10. 1016/j.apenergy.2017.08.228

Adhikari M, Ghimire LP, Kim Y et al (2020) Identification and analysis of barriers against electric vehicle use. Sustain 12:1-20. https:// doi.org/10.3390/SU12124850

AEPC (2008) Solar and Wind Energy Resource Assessment in Nepal (SWERA) Final Report (GIS PART). Lalitpur. .https://policy. asiapacificenergy.org/sites/default/files/Assessment__Solar and Wind Energy Resource- in Nepal \%282008\%29_reduced.pdf

Ahmad F, Alam MS, Alsaidan IS, Shariff SM (2020) Battery swapping station for electric vehicles: Opportunities and challenges. IET Smart Grid 3:280-286. https://doi.org/10.1049/iet-stg.2019.0059

Ahmad F, Alam MS, Shariff SM, Krishnamurthy M (2019) A costefficient approach to EV charging station integrated community microgrid: a case study of indian power market. IEEE Trans Transp Electrif 5:200-214. https://doi.org/10.1109/TTE.2019. 2893766

Ahmad F, Khalid M, Panigrahi BK (2021a) Development in energy storage system for electric transportation: a comprehensive review. J Energy Storage 43:103153. https://doi.org/10.1016/J. EST.2021.103153

Ahmad F, Khalid M, Panigrahi BK (2021b) An enhanced approach to optimally place the solar powered electric vehicle charging station in distribution network. J Energy Storage 42:103090. https:// doi.org/10.1016/J.EST.2021.103090

Amin A, Tareen WUK, Usman M et al (2020) A review of optimal charging strategy for electric vehicles under dynamic pricing schemes in the distribution charging network. Sustain 12:1-28. https://doi.org/10.3390/su122310160

Asaad M, Ahmad F, Alam MS, Sarfraz M (2019) Smart grid and Indian experience: a review. Resour Policy 74:101499. https://doi.org/ 10.1016/J.RESOURPOL.2019.101499

Balakrishna P, Swarup KS (2020) A method of low voltage residential micro-grids management using AMI/GIS systems and its application benefits. Renew Energy Focus 32:1-9. https://doi.org/10. 1016/j.ref.2019.10.004
Baldick R, O'Neill RP (2009) Estimates of comparative costs for uprating transmission capacity. IEEE Trans Power Deliv 24:961-969. https://doi.org/10.1109/TPWRD.2008.2002990

Bhusal R (2020) Solar power project in Butwal starts commercial power generation. In: myRepublica. https://myrepublica.nagar iknetwork.com/news/solar-power-project-in-butwal-startscommercial-power-generation/. Accessed 5 Jul 2021

Bibak B, Tekiner-Moğulkoç H (2021) A comprehensive analysis of Vehicle to Grid (V2G) systems and scholarly literature on the application of such systems. Renew Energy Focus 36:1-20. https://doi.org/10.1016/j.ref.2020.10.001

Birleanu FG, Bizon N (2020) Control and protection of the smart microgrids using Internet of Things: technologies, architecture and applications. Power Syst 749:770. https://doi.org/10.1007/ 978-3-030-23723-3 31

Blanco G, Olsina F, Garcés F, Rehtanz C (2011) Real option valuation of FACTS investments based on the least square Monte Carlo method. IEEE Trans Power Syst 26:1389-1398. https://doi.org/ 10.1109/TPWRS.2010.2094211

Bolduc A, Weihe M Von, Smith J, Dise S (2020) Utility best practices for EV infrastructure deployment. Washington DC. .https://sepap ower.org/resource/best-practices-for-utility-ev-infrastructuredeployment/

BPDB (2019) BPDB Annual Report FY 2019-20.https://www.bpdb. gov.bd/bpdb_new/index.php/site/new_annual_reports

CEB (2018) Annual Report 2018.https://ceb.lk/publication-media/ annual-reports/en

Cheng AJ, Tarroja B, Shaffer B, Samuelsen S (2018) Comparing the emissions benefits of centralized vs. decentralized electric vehicle smart charging approaches: a case study of the year 2030 California electric grid. J Power Sources 401:175-185. https:// doi.org/10.1016/j.jpowsour.2018.08.092

DoED (2021) Construction license :: Solar. https://www.doed.gov.np/ license/23. Accessed 5 Jul 2021

DoED (2022) Power plants :: Hydro (More than 1MW). https://www. doed.gov.np/license/54. Accessed 19 Jan 2022

Dranka GG, Ferreira P (2020) Towards a smart grid power system in Brazil: challenges and opportunities. Energy Policy 136:111033. https://doi.org/10.1016/j.enpol.2019.111033

Duarte M (2020) Economic appraisal and cost-benefit analysis. In: Nilsson SL (ed) Andersen BR. Springer, Paris, pp 709-751

Edris AA, Adapa R, Baker MH, et al (1997) Proposed terms and definitions for Flexible AC Transmission System (FACTS). IEEE Trans Power Deliv. https://doi.org/10.1109/61.634216

EPRI (2011) Estimating the costs and benefits of the smart grid: a preliminary estimate of the investment requirements and the resultant benefits of a fully functioning smart grid.https://smartgrid. gov/files/documents/Estimating_Costs_Benefits_Smart_Grid_ Preliminary_Estimate_In_201103.pdf

Fallahzadeh-Abarghouei H, Hasanvand S, Nikoobakht A, Doostizadeh M (2018) Decentralized and hierarchical voltage management of renewable energy resources in distribution smart grid. Int J Electr Power Energy Syst 100:117-128. https://doi.org/10.1016/j.ijepes. 2018.02.006

Firouzjah KG, Ahmadiahangar R, Rosin A, Haring T (2019) A fast current harmonic detection and mitigation strategy for shunt active filter. In: 2019 Electric Power Quality and Supply Reliability Conference and 2019 Symposium on Electrical Engineering and Mechatronics, PQ and SEEM 2019. Institute of Electrical and Electronics Engineers Inc.

Fuentes S, Villafafila-Robles R, Olivella-Rosell P et al (2020) Transition to a greener Power Sector: four different scopes on energy security. Renew Energy Focus 33:23-36. https://doi.org/10. 1016/j.ref.2020.03.001 
Galus MD, Vayá MG, Krause T, Andersson G (2013) The role of electric vehicles in smart grids. Wiley Interdiscip Rev Energy Environ 2:384-400. https://doi.org/10.1002/wene.56

Gandoman FH, Ahmadi A, Sharaf AM et al (2018) Review of FACTS technologies and applications for power quality in smart grids with renewable energy systems. Renew Sustain Energy Rev 82:502-514. https://doi.org/10.1016/j.rser.2017.09.062

GGGI (2018) National Action Plan for Electric Mobility: accelerating implementation of Nepal's nationally determined contribution. Seoul. .https://gggi.org/site/assets/uploads/2018/07/GGGINepal_Action-Plan-for-Electric-Mobility.pdf

Ghiasi M (2019) Technical and economic evaluation of power quality performance using FACTS devices considering renewable micro-grids. Renew Energy Focus 29:49-62. https://doi.org/10. 1016/j.ref.2019.02.006

GoN (2021) Nepal Budget Statement FY 2021/22. Kathmandu. .http:// pkf.trunco.com.np/uploads/publication/file/PKFTRUBudgetHig hlights207879_20210615064644.pdf

GoN (2018a) Current situation of energy, water resources and irrigation sector and future mapping (white paper). Kathmandu

GoN (2016) Nationally determined contributions. Kathmandu. .https:// www4.unfccc.int/sites/ndcstaging/PublishedDocuments/Nepal First/Nepal First NDC.pdf

GoN (2018b) Accelerating implementation of Nepal's nationally determined contribution investment projects for electric mobilitY. Kathmandu. .https://gggi.org/site/assets/uploads/2020/02/ GGGI_Nepal_Investment-Projects-for-Electric-Mobility_Final. pdf

GoN (2015) Nepal Water Supply, Sanitation and Hygiene Sector Development Plan (2016-2030). Kathmandu. .http://mowss.gov.np/ assets/uploads/files/SDP_-_Final-_Eng.pdf (accessed october, 2021)

Gorjian S, Ebadi H, Trommsdorff M et al (2021) The advent of modern solar-powered electric agricultural machinery: a solution for sustainable farm operations. J Clean Prod 292:126030. https:// doi.org/10.1016/j.jclepro.2021.126030

Gorjian S, Ghobadian B (2015) Solar thermal power plants: progress and prospects in Iran. Energy Procedia 75:533-539. https://doi. org/10.1016/j.egypro.2015.07.447

Gorjian S, Zadeh BN, Eltrop L et al (2019) Solar photovoltaic power generation in Iran: development, policies, and barriers. Renew Sustain Energy Rev 106:110-123. https://doi.org/10.1016/j.rser. 2019.02.025

Helmus JR, Spoelstra JC, Refa N et al (2018) Assessment of public charging infrastructure push and pull rollout strategies: the case of the Netherlands. Energy Policy 121:35-47. https://doi.org/10. 1016/J.ENPOL.2018.06.011

Hildermeier J, Kolokathis C, Rosenow J et al (2019) Smart ev charging: a global review of promising practices. World Electr Veh J 10:1-13. https://doi.org/10.3390/wevj10040080

Himalayan News Service (2020) Electricity consumption increases to 267 units. In: Himal. Times. https://thehimalayantimes. com/business/electricity-consumption-increases-to-267-units. Accessed $11 \mathrm{Jul} 2021$

IEA (2019) Data and statistics.https://www.iea.org/data-and-statistics

IRENA (2018) Global energy transformation: a roadmap to 2050. Abu Dhabi. ISBN:1059-910X

IRENA (2021a) Renewable capacity highlights. Abu Dhabi. .www. irena.org/publications.

IRENA (2021b) Renewable capacity statistics. Abu Dhabi. ISBN:978-92-9260-342-7

Islam N, Bloemink J (2018) Bangladesh' s energy crisis : a summary of challenges and smart grid -based solutions. In: 2018 2nd International Conference on Smart Grid and Smart Cities (ICSGSC). IEEE, pp 111-116
Jha AK, Bajracharya TR (2014) Wastewater treatment technologies. In: IOE Graduate Conference. Kathmandu

Jian L, Zheng Y, Shao Z (2017) High efficient valley-filling strategy for centralized coordinated charging of large-scale electric vehicles. Appl Energy 186:46-55. https://doi.org/10.1016/j.apenergy. 2016.10.117

Kainuma M, Pandey R, Masui T, Nishioka S (2017) Methodologies for leapfrogging to low carbon and sustainable development in Asia. J Renew Sustain Energy DOI 10(1063/1):4978469

Kappagantu R, Daniel SA (2018) Challenges and issues of smart grid implementation: a case of Indian scenario. J Electr Syst Inf Technol 5:453-467. https://doi.org/10.1016/j.jesit.2018.01.002

Kempton W, Letendre SE (1997) Electric vehicles as a new power source for electric utilities. Transp Res Part D Transp Environ 2:157-175. https://doi.org/10.1016/S1361-9209(97)00001-1

Khan MSA, Kadir KM, Mahmood KS et al (2019a) Technical investigation on $\mathrm{V} 2 \mathrm{G}, \mathrm{S} 2 \mathrm{~V}$, and V2I for next generation smart city planning. J Electron Sci Technol 17:100010. https://doi.org/10. 1016/J.JNLEST.2020.100010

Khan S, Ahmad A, Ahmad F et al (2018a) A comprehensive review on solar powered electric vehicle charging system. Smart Sci 6:54-79. https://doi.org/10.1080/23080477.2017.1419054

Khan W, Ahmad A, Ahmad F, Saad Alam M (2018b) A comprehensive review of fast charging infrastructure for electric vehicles. Smart Sci 6:256-270. https://doi.org/10.1080/23080477.2018.1437323

Khan W, Ahmad F, Alam MS (2019b) Fast EV charging station integration with grid ensuring optimal and quality power exchange. Eng Sci Technol an Int J 22:143-152. https://doi.org/10.1016/J. JESTCH.2018.08.005

L'Abbate A, Fulli G, Handschin E (2007) Economics of FACTS integration into the liberalised European power system. 2007 IEEE Lausanne Power Tech

Lemar P, De Fontaine A (2017) Energy data management manual for the wastewater treatment sector.betterbuildingsinitiative.energy. gov

Liao JT, Huang HW, Yang HT, Li D (2021) Decentralized v2g/g2v scheduling of ev charging stations by considering the conversion efficiency of bidirectional chargers. Energies 14(4):962. https:// doi.org/10.3390/en 14040962

Liu BC, Ieee M, Chau KT et al (2013) Opportunities and challenges of vehicle-to-home, vehicle-to-grid technologies. Proc IEEE 101(11):1-19. https://doi.org/10.1109/JPROC.2013.2271951

Luo Y, Zhu T, Cao K, Li K (2013) The impacts of large scale electric vehicles charging behaviour on distribution system and local traffic system. In: IFAC Proceedings Volumes (IFAC-PapersOnline). IFAC, pp 651-657

Mamut T, Badea A (2015) Smart power generation in wastewater treatment plants. UPB Sci Bull Ser C Electr Eng Comput Sci 77:255-268

Massoud Amin S, Wollenberg BF (2005) Toward a smart grid: power delivery for the 21st century. IEEE Power Energy Mag. https:// doi.org/10.1109/mpae.2005.1507024

Moazeni F, Khazaei J (2021) Co-optimization of wastewater treatment plants interconnected with smart grids. Appl Energy 298:117150. https://doi.org/10.1016/j.apenergy.2021.117150

MoPE (2016) Renewable Energy Subsidy Policy. Gov Nepal , Minist Popul Environ

MyRepublica (2020) Over 86 percent households have now access to electricity through national grid. myRepublica

NACAA (2015) Reduce losses in the transmission and distribution system.https://www.4cleanair.org/wp-content/uploads/Docum ents/Chapter_10.pdf

NEA (2021) A year in review fiscal year 2020/21. Nepal Electr Auth 9-10 
NEA (2020) A year in review: fiscal year 2019/20. Kathmandu. .https:// www.nea.org.np/annual_report

Panwar U, Kumar A, Chakrabarti D (2019) Barriers in implementation of electric vehicles in India. Int J Electr Hybrid Veh 11:195-204. https://doi.org/10.1504/IJEHV.2019.101273

Patil H, Kalkhambkar VN (2020) Charging cost minimisation by centralised controlled charging of electric vehicles. Int Trans Electr Energy Syst 30:1-13. https://doi.org/10.1002/2050-7038.12226

Paudel DP (2019) Present status and utilization of the mineral resources in Nepal. Third Pole J Geogr Educ 18:85-96. https://doi.org/10. 3126/ttp.v18i0.28009

Peng FZ, Wang J (2019) Flexible transmission and resilient distribution systems enabled by power electronics. In: Bose BK (ed) Power Electronics in Renewable Energy Systems and Smart Grid, 1st edn. John Wiley \& Sons Inc, pp 271-314

Ponce-Jara MA, Ruiz E, Gil R et al (2017) Smart Grid: assessment of the past and present in developed and developing countries. Energy Strateg Rev 18:38-52. https://doi.org/10.1016/j.esr.2017. 09.011

Poudyal R, Loskot P, Nepal R et al (2019) Mitigating the current energy crisis in Nepal with renewable energy sources. Renew Sustain Energy Rev 116:109388. https://doi.org/10.1016/j.rser.2019. 109388

Pourmousavi SA, Cifala AS, Nehrir MH (2012) Impact of high penetration of PV generation on frequency and voltage in a distribution feeder. In: 2012 North American Power Symposium, NAPS 2012

Quak H, Nesterova N, Van Rooijen T (2016) Possibilities and barriers for using electric-powered vehicles in city logistics practice. Transp Res Procedia 12:157-169. https://doi.org/10.1016/j.trpro. 2016.02.055

Quintero Pulido DF, Barreto CM, Ten Kortenaar MV et al (2018) Simulation of sizing of energy storage for off-grid decentralized wastewater treatment units: a case study in the Netherlands. Water Pract Technol 13:771-779. https://doi.org/10.2166/wpt. 2018.087

Rajper SZ, Albrecht J (2020) Prospects of electric vehicles in the developing countries: a literature review. Sustain 12(5):1906. https:// doi.org/10.3390/su12051906

Ramtel P, Tamang T, Pokhrel N et al (2021) Wastewater and biogas production in Kathmandu valley, Nepal: challenges and opportunities. Environ Eng Manag J 20:257-266

Regmi S (2013) Wastewater treatment in Kathmandu management, treatment and alternative. Mikkeli University of Aplied Sciences

RPGCL (2020) Nepal Transmission Network Map. Kathmandu. .https://moewri.gov.np/storage/listies/May2020/nepal-powertransmission-network-map.pdf

Schneider KP, Laval S, Hansen J et al (2019) A distributed power system control architecture for improved distribution system resiliency. IEEE Access 7:9957-9970. https://doi.org/10.1109/ ACCESS.2019.2891368

Shariff SM, Alam MS, Ahmad F et al (2020) System Design and Realization of a Solar-Powered Electric Vehicle Charging Station. IEEE Syst J 14:2748-2758. https://doi.org/10.1109/JSYST. 2019.2931880

Shrestha A, Bishwokarma R, Chapagain A et al (2019) Peer-to-peer energy trading in micro/mini-grids for local energy communities: a review and case study of Nepal. IEEE Access 7:131911131928. https://doi.org/10.1109/ACCESS.2019.2940751

Shrestha K, Shrestha PP, Shrestha G (2017) Carbon dioxide emissions by the transportation sector and its impact on health in the Kathmandu Valley, Nepal. J Civ Eng Archit 11:184-193. https://doi.org/10.17265/1934-7359/2017.02.009

Shrestha S, Nakarmi M (2015) Demand side management for electricity in Nepal: need analysis using LEAP Modeling Framework. Proc IOE Grad Conf 2015 Nepal 242-251
Simões MG, Roche R, Kyriakides E, et al (2011) Smart-grid technologies and progress in Europe and the USA. IEEE Energy Convers Congr Expo Energy Convers Innov a Clean Energy Futur ECCE 2011, Proc 383-390. https://doi.org/10.1109/ ECCE.2011.6063795

Singh G, Tiwari AN (2017) A review on smart grid initiatives and power structure in India 2017 1st Int. Conf Electron Mater Eng Nano-Technology Iementech 2017:1515302. https://doi.org/10. 1109/IEMENTECH.2017.8077006

Sovacool BK, Dhakal S, Gippner O, Bambawale MJ (2011) Halting hydro: a review of the socio-technical barriers to hydroelectric power plants in Nepal. Energy 36:3468-3476. https://doi.org/ 10.1016/j.energy.2011.03.051

Spataru C, Bouffaron P (2016) Off-grid energy storage. Storing Energy 477:497. https://doi.org/10.1016/B978-0-12-8034408/00022-1

Sung J, Park S, Nam K (2000) New hybrid parallel active filter configuration minimising active filter size. In: IEEE ProceedingsElectric Power Applications

Surendra KC, Khanal SK, Shrestha P, Lamsal B (2011) Current status of renewable energy in Nepal: opportunities and challenges. Renew Sustain Energy Rev 15:4107-4117. https://doi.org/10. 1016/j.rser.2011.07.022

The Economic Times (2021) Economic Survey 2020-21 flags high T\&D losses in power sector. In: Energy World. https://energy. economictimes.indiatimes.com/news/power/economic-survey-2020-21-flags-high-td-losses-in-power-sector/80595833. Accessed 28 Jul 2021

The Himalayan Times (2021) EDITORIAL: charging stations. In: Himal. Times. https://thehimalayantimes.com/opinion/editorialcharging-stations. Accessed 31 May 2021

The Kathmandu Post (2018) Power distribution system to be outdated in 2 years. In: Kathmandu Post. https://kathmandupost.com/ money/2018/02/23/power-distribution-system-to-be-outdatedin-2-years. Accessed 21 Nov 2020

The World Bank (2018) Electric power transmission and distribution losses (\% of output)| Data. https://data.worldbank.org/indicator/ EG.ELC.LOSS.ZS?end=2014\&locations $=$ TG\&start $=1971$. Accessed 7 Oct 2020

The World Bank (2020) GDP growth (annual \%) - Nepal I Data. https:// data.worldbank.org/indicator/NY.GDP.MKTP.KD.ZG?locat ions $=$ NP. Accessed 9 Jul 2021

The World Bank (2013) Nepal - Electricity Transmission Network. https://datacatalog.worldbank.org/dataset/nepal-electricity-trans mission-network-2013. Accessed 5 Jul 2021

Tu C, He X, Shuai Z, Jiang F (2017) Big data issues in smart grid - a review. Renew Sustain Energy Rev 79:1099-1107. https://doi. org/10.1016/j.rser.2017.05.134

Uddin SN, Taplin R (2006) A sustainable energy future in Bangladesh : current situation and need for effective strategies 2 . CLIMATE CHANGE AND CLIMATE IMPACTS 3 . ENVIRONMENTAL IMPACTS FROM ENERGY SYSTEMS. In: Sustainable Energy and Environment. Bangkok, pp 1-7

UNESCO (2017) The United Nation World Water Development Report 2017.http://www.unesco.org/new/en/natural-sciences/ environment/water/wwap/wwdr/2017-wastewater-the-untap ped-resource/

Vaya MG, Andersson G (2012) Centralized and decentralized approaches to smart charging of plug-in vehicles. IEEE Power Energy Soc Gen Meet 1:8. https://doi.org/10.1109/PESGM.2012. 6344902

Vesnic-Alujevic L, Breitegger M, Pereira ÂG (2016) What smart grids tell about innovation narratives in the: hopes, imaginaries and policy. Energy Res Soc Sci 12:16-26. https://doi.org/10.1016/j. erss.2015.11.011 
WECS (2017) Electricity Demand Forecast Report (2015-2040). Kathmandu. .http://www.wecs.gov.np/uploaded/Electricity-DemandForecast-Report-2014-2040.pdf

Xu S, Yan Z, Feng D, Zhao X (2019) Decentralized charging control strategy of the electric vehicle aggregator based on augmented Lagrangian method. Int J Electr Power Energy Syst 104:673679. https://doi.org/10.1016/j.ijepes.2018.07.024

Yadav A, Pal N, Patra J, Yadav M (2020) Strategic planning and challenges to the deployment of renewable energy technologies in the world scenario: its impact on global sustainable development. Environ Dev Sustain 22:297-315. https://doi.org/10.1007/ s10668-018-0202-3

Yan P, Qin RC, Guo JS et al (2017a) Net-zero-energy model for sustainable wastewater treatment. Environ Sci Technol 51:10171023. https://doi.org/10.1021/acs.est.6b04735

Yan S, Tan SC, Lee CK, et al (2017b) Use of smart loads for power quality improvement. In: IEEE Journal of Emerging and Selected
Topics in Power Electronics. Institute of Electrical and Electronics Engineers Inc., pp 504-512

Yoldaş Y, Önen A, Muyeen SM et al (2017) Enhancing smart grid with microgrids: challenges and opportunities. Renew Sustain Energy Rev 72:205-214. https://doi.org/10.1016/j.rser.2017.01.064

Zhang X-P, Rehtanz C, Pal B (2012) Flexible AC transmission systems: modelling and control. Springer, Berlin Heidelberg. https://doi. org/10.1007/978-3-642-28241-6

Zhou A, Zhou W, Manandhar P (2020) A study on the prospect of hydropower to hydrogen in Nepal.https://www.adb.org/publicatio ns/study-hydropower-hydrogen-nepal

Publisher's note Springer Nature remains neutral with regard to jurisdictional claims in published maps and institutional affiliations. 